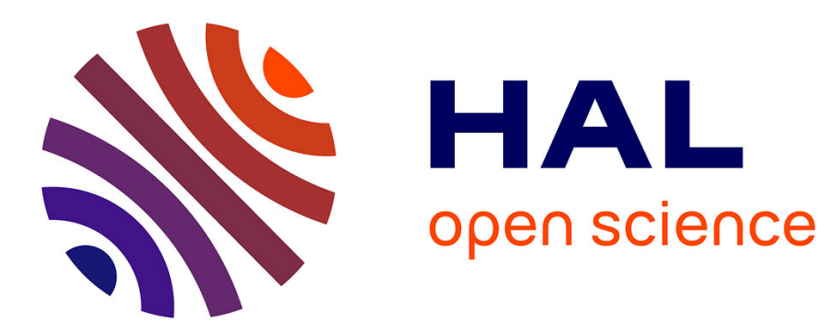

\title{
Plasma-liquid interfacial layer detected by in situ Raman light sheet microspectroscopy \\ David Z Pai
}

\section{To cite this version:}

David Z Pai. Plasma-liquid interfacial layer detected by in situ Raman light sheet microspectroscopy. Journal of Physics D: Applied Physics, 2021, 54 (35), pp.355201. 10.1088/1361-6463/ac07e0 . hal03268029

\section{HAL Id: hal-03268029 \\ https://hal.science/hal-03268029}

Submitted on 22 Jun 2021

HAL is a multi-disciplinary open access archive for the deposit and dissemination of scientific research documents, whether they are published or not. The documents may come from teaching and research institutions in France or abroad, or from public or private research centers.
L'archive ouverte pluridisciplinaire HAL, est destinée au dépôt et à la diffusion de documents scientifiques de niveau recherche, publiés ou non, émanant des établissements d'enseignement et de recherche français ou étrangers, des laboratoires publics ou privés. 
ACCEPTED MANUSCRIPT

\section{Plasma-liquid interfacial layer detected by in situ Raman light sheet microspectroscopy}

To cite this article before publication: David Z Pai 2021 J. Phys. D: Appl. Phys. in press https://doi.org/10.1088/1361-6463/ac07e0

\section{Manuscript version: Accepted Manuscript}

Accepted Manuscript is "the version of the article accepted for publication including all changes made as a result of the peer review process, and which may also include the addition to the article by IOP Publishing of a header, an article ID, a cover sheet and/or an 'Accepted Manuscript' watermark, but excluding any other editing, typesetting or other changes made by IOP Publishing and/or its licensors"

This Accepted Manuscript is @ 2021 IOP Publishing Ltd.

During the embargo period (the 12 month period from the publication of the Version of Record of this article), the Accepted Manuscript is fully protected by copyright and cannot be reused or reposted elsewhere.

As the Version of Record of this article is going to be / has been published on a subscription basis, this Accepted Manuscript is available for reuse under a CC BY-NC-ND 3.0 licence after the 12 month embargo period.

After the embargo period, everyone is permitted to use copy and redistribute this article for non-commercial purposes only, provided that they adhere to all the terms of the licence https://creativecommons.org/licences/by-nc-nd/3.0

Although reasonable endeavours have been taken to obtain all necessary permissions from third parties to include their copyrighted content within this article, their full citation and copyright line may not be present in this Accepted Manuscript version. Before using any content from this article, please refer to the Version of Record on IOPscience once published for full citation and copyright details, as permissions will likely be required. All third party content is fully copyright protected, unless specifically stated otherwise in the figure caption in the Version of Record.

View the article online for updates and enhancements. 


\title{
Plasma-liquid interfacial layer detected by in situ Raman light sheet microspectroscopy
}

\author{
David Z. Pai ${ }^{1,2}$ \\ France \\ ${ }^{1}$ Corresponding author: david.pai@1pp.polytechnique.fr
}

Institut Pprime (CNRS-Université de Poitiers-ENSMA), F-86962 Futuroscope Chasseneuil,

\begin{abstract}
In situ Raman microscopy has been adapted to study the plasma-water interface by applying a light sheet technique. The Raman modes of the -OO stretch of $\mathrm{H}_{2} \mathrm{O}_{2}$, symmetric stretch $\left(v_{1}\right)$ of $\mathrm{NO}_{3}{ }^{-}$, and $-\mathrm{OH}$ bend of water were measured simultaneously. By modulating the volume of water under detection, both the bulk liquid and interface regions have been probed with micrometer depth resolution. The plasma was a DC glow discharge generated in atmospheric-pressure air with a water cathode. In the bulk liquid, the molar concentration of aqueous $\mathrm{NO}_{3}{ }^{-}$increased at a linear rate of $48 \mu \mathrm{M} /$ minute, whereas aqueous $\mathrm{H}_{2} \mathrm{O}_{2}$ growth stopped at about $5 \mathrm{mM}$. The concentrations of $\mathrm{H}_{2} \mathrm{O}_{2}$ and $\mathrm{NO}_{3}{ }^{-}$both increased when measuring at depths less than about $20 \mu \mathrm{m}$ from the interface. The depth profile of $\mathrm{NO}_{3}$ concentration was reconstructed, showing that the interfacial layer of $\mathrm{NO}_{3}{ }^{-}$has a depth of $28 \mu \mathrm{m}$. The shape of the meniscus may influence the interpretation of this depth. Previous models of plasma-water interfaces have predicted interfacial layers of similar depth for short-lived aqueous species such as $\mathrm{OH}$ but not for long-lived species such as $\mathrm{NO}_{3}{ }^{-}$.
\end{abstract}

Keywords: plasma-activated water (PAW), pulsed Raman, nitrate anion, hydrogen peroxide

${ }^{2}$ Current affiliation: LPP, CNRS, École Polytechnique, Sorbonne Université, Université Paris-Saclay, IPParis, 91128 Palaiseau, France 
Revised manuscript to Journal of Physics D

\section{Introduction}

The chemistry of plasma-activated water (PAW) has been under investigation for an expanding number of potential applications such as the deactivation of airborne respiratory syndrome viruses (Nayak et al. 2020), bacterial deactivation (Kamgang-Youbi et al. 2008, Machala et al. 2013), agriculture (Zhou et al. 2016, Zhang et al. 2017), water treatment (Liu et al. 2018), cancer treatment (Chen et al. 2016, Girard et al. 2016b), and nanomaterials synthesis (Yang et al. 2019, Orriere et al. 2020). Plasma chemistry leads to the formation of gas-phase species that undergo a cascade of processes in the liquid to produce aqueous species such as $\mathrm{H}_{2} \mathrm{O}_{2}, \mathrm{ONOOH}$, $\mathrm{NO}_{2}{ }^{-}$, and $\mathrm{NO}_{3}^{-}$(Machala et al. 2018).

The liquid-phase diagnostics of the plasma-water interfacial region can provide new insight into how the plasma transforms water into PAW. (Gorbanev et al. 2018) and (Zhou et al. 2020) review several major categories of experimental techniques used for the analysis of liquid chemistry: electron spin resonance spectroscopy (Tresp et al. 2013, Jablonowski et al. 2018), liquid chromatography/mass spectrometry (Lukes et al. 2014), and optical spectrophotometry (Girard et al. 2016a, Tachibana and Yasuoka 2020). These techniques suffer variously from a lack of selectivity and/or degradation of dyes, chemical probes, or spin traps/probes introduced into the liquid. The spatial distribution of species is not accessible except in the case of spectrophotometry. Most importantly, the majority of the diagnostics must be performed ex situ, removed from the plasma reactor and after treatment.

Recently, the in situ measurement of solvated electrons has attracted much attention, and techniques such as total internal reflection absorption (Rumbach et al. 2015b, Rumbach et al. 2015a) and charge transfer to the solvent (Inagaki and Sasaki 2020) have been developed for this purpose. In particular, the former is capable of detecting a surface layer several nanometers thick and is currently one of the only techniques for the spatially resolved characterization of the interface. Recent models have shown that the interfacial region is structured at different depths (Tian and Kushner 2014, Lindsay et al. 2015, Liu et al. 2015, Gopalakrishnan et al. 2016, Rumbach et al. 2018, Verlackt et al. 2018, Heirman et al. 2019), due to both chemistry and transport. However, so far there has been a limited variety of experimental tools for validating these models.

In situ spontaneous Raman spectroscopy offers several important advantages over the aforementioned diagnostic tools. It can be completely non-intrusive at the appropriate laser wavelength and power, as well as highly selective if the Raman spectrum of each species is 
Revised manuscript to Journal of Physics D

unambiguous. A wide range of species may be detectable, provided they are Raman-active and produce sufficient signal strength. Calibration in absolute concentration against reference solutions can be straightforward. Finally, high spatial resolution is possible, as will be demonstrated in this work.

Potential drawbacks include interference from photoluminescence spectra excited along with the Raman spectra, although this is not a problem in the present study. The spontaneous Raman effect is inherently weak, limiting detection here to about $1 \mathrm{mM}$, even for a scatterer with a high cross section such as $\mathrm{NO}_{3}{ }^{-}$. By comparison, detection thresholds of $1 \mu \mathrm{M}$ or less are possible using colorimetry (Tachibana and Yasuoka 2020) or ion chromatography (Lukes et al. 2014). However, higher laser power, a more sensitive detector, and/or longer integration time could significantly lower the detection limit of Raman spectroscopy.

Raman spectroscopy has been an established tool for the determination of the gas temperature of non-thermal plasmas (Verreycken et al. 2011, Lo et al. 2014). Less common has been the in situ Raman characterization of a condensed phase in contact with such a plasma, even though ex situ measurement is routine. Relevant previous studies include the stimulated Raman scattering (SRS) of the $-\mathrm{OH}$ stretch mode of water produced at laser power densities of $\sim 10^{11}$ $\mathrm{W} / \mathrm{cm}^{2}$, which is high enough to induce laser-induced breakdown at air-water interfaces (Yui et al. 2002, Yui et al. 2008, Li et al. 2015). However, in all of these cases, SRS occurs before plasma formation (Yui et al. 1999), when a very high electron density believed to be $10^{20} \mathrm{~cm}^{-3}$ enhances the Raman scattering of water that is still in the liquid phase. Previous work on in situ Raman probing of dense media in the presence of electrical discharges include dielectric barrier discharges generated in supercritical $\mathrm{CO}_{2}$ (Tomai et al. 2009, Pai et al. 2015), as well as the monitoring of nanomaterial growth by plasmas (Labbaye et al. 2014, Pai et al. 2019).

The objective of the present study is to develop Raman spectroscopy as an in situ diagnostic technique for resolving the spatial structure of the liquid side of the plasma-water interface, in terms of its physical/chemical properties and species concentrations. The discharge under study is a glow discharge generated in open atmospheric-pressure air over a static reservoir of water (section 2.1). A pulsed laser was employed along with gated detection to suppress interference from plasma emission (section 2.2). Light sheet microscopy was employed to acquire depth profiles with $\sim 1 \mu \mathrm{m}$ resolution (section 2.3), with careful attention paid to the shape of the detection volume (section 2.4). The Raman spectra of water, $\mathrm{NO}_{3}{ }^{-}$, and $\mathrm{H}_{2} \mathrm{O}_{2}$ were tracked simultaneously 
Revised manuscript to Journal of Physics D

in real time in a fashion that reveals the chemistry of the interfacial layer within $\sim 20 \mu \mathrm{m}$ of the water surface to be different from the bulk liquid (sections 3.1 and 3.2). The results will be compared to previous work on the chemistry of the bulk (section 4.1) and interfacial (section 4.2) regions of closely related PAW reactors.

\section{Experimental setup}

\subsection{Discharge circuit}

As shown in Figure 1, the plasma was generated in open ambient air by applying a positive DC voltage to a sharpened tungsten tip that was positioned above a $24 \mathrm{~mL}$ optically polished quartz cell (Spectrosil Far UV Quartz, Starna Dye Laser Cell) filled nearly completely with ultrapure water (Elga LabWater Purelab Flex 18.2 M $\Omega \cdot \mathrm{cm},<0.15 \mathrm{mg} / \mathrm{L}$ total organic carbon). The DC power supply (Stanford Research Systems PS350) output a constant voltage of $+5.0 \mathrm{kV}$, and the gap distance between the tungsten tip and the water surface was adjusted to maintain a DC current output of $4.10-4.67 \mathrm{~mA}$. A 1-M $\Omega$ resistor limited the current and stabilized the discharge. A grounded platinum wire (Goodfellow) was immersed roughly $2 \mathrm{~cm}$ away from the tungsten tip, completing the discharge circuit. The voltage applied at the tungsten tip, measured by a highvoltage probe (Lecroy PPE $6 \mathrm{kV}, 400 \mathrm{MHz}$ bandwidth) and recorded on an oscilloscope (Rohde \& Schwarz RTO 1024, $2 \mathrm{GHz}$ bandwidth), can exhibit fluctuations up to $\sim 1 \mathrm{kV}$ in amplitude at a characteristic frequency of $\sim 100 \mathrm{kHz}$ (see Supplementary Information). Measurements using a current transformer (Bergoz CT-D5.0, 4.8 kHz - $400 \mathrm{MHz}$ passband) isolated the corresponding transient current component. The total current was measured using a $50-\Omega$ current-sensing resistor inserted in series between the platinum wire and ground. The power fluctuations shown in Figure 1 represent one of several characteristic types in terms of amplitude and frequency. Over the course of plasma treatment, the current-voltage waveforms can range from true DC to self-pulsed with an instantaneous power of hundreds of watts, although the majority of fluctuation types are about 1 $\mathrm{W}$ in magnitude. The average power dissipated by the discharge and water together evolves gradually over time and can range from 3 to $6 \mathrm{~W}$. 
Revised manuscript to Journal of Physics D

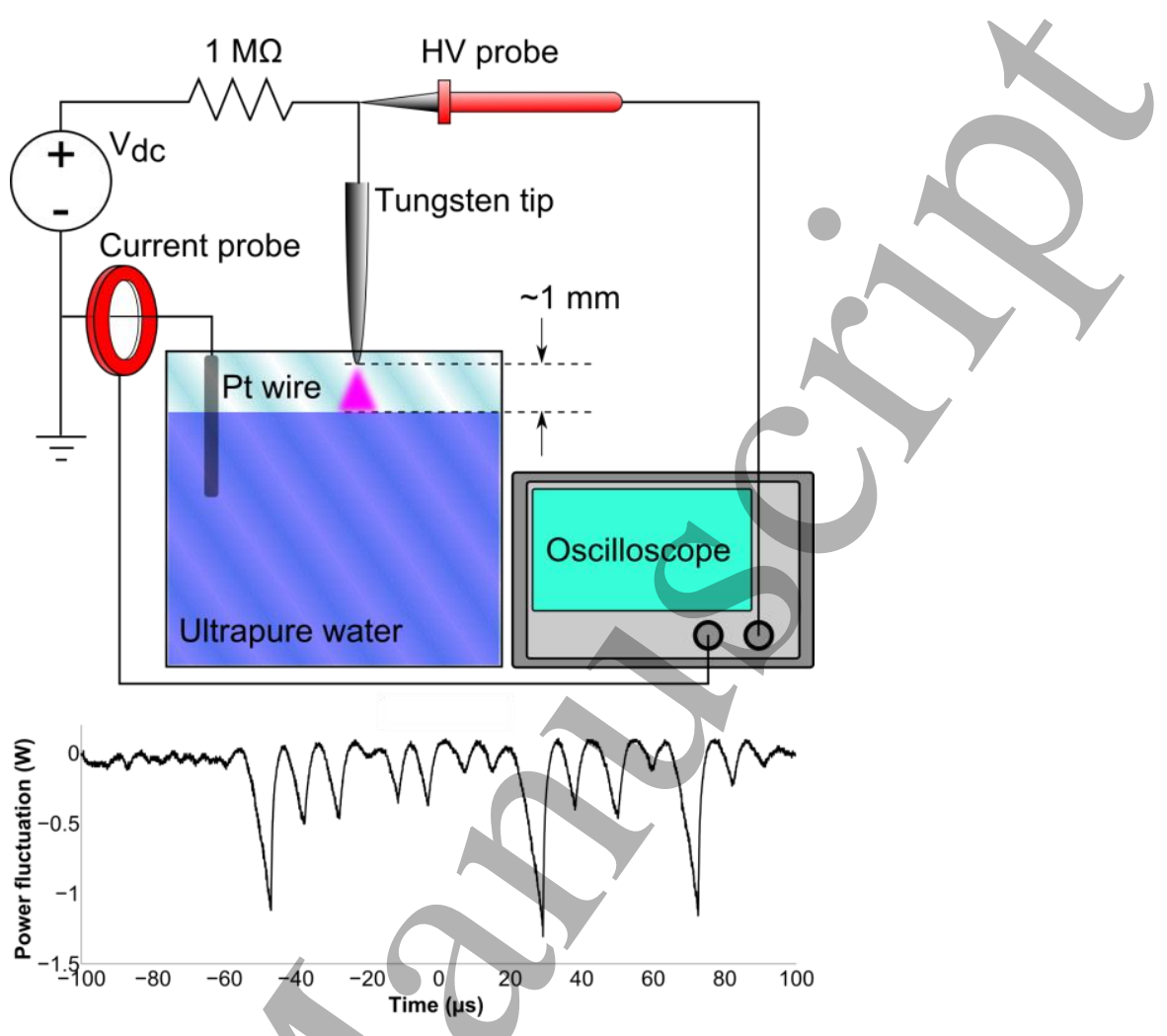

Figure 1: Schematic diagram of the discharge circuit (top). Example waveform of the power fluctuation (bottom), measured long after the initial breakdown of fresh water. The underlying DC power is $5.7 \pm 0.4 \mathrm{~W}$.

Previous studies have thoroughly characterized the properties of DC glow air plasmas generated in direct contact with distilled water reservoirs, without refreshment. The fluctuating electrical characteristics at short time scales (Figure 1) are qualitatively similar to those from (Bruggeman et al. 2007). Within minutes, the water temperature of such a reactor stabilizes to $60^{\circ} \mathrm{C}$, and the $\mathrm{pH}$ decreases to 2 (Bruggeman et al. 2008). The conductivity increases steadily and exceeds $100 \mu \mathrm{S} / \mathrm{cm}$ after 1 hour. The water evaporation rate varies with the discharge current, even though the gas temperature (based on the rotational temperature of the $\mathrm{N}_{2}(C)$ state) remains about constant at $1600 \pm 100 \mathrm{~K}$ (Sirotkin and Titov 2017). At a discharge current of $10 \mathrm{~mA}$, the electric field in the positive column and cathode fall voltage are $1.2 \mathrm{kV} / \mathrm{cm}$ and $680 \mathrm{~V}$, respectively. Both quantities should increase with lower current. For the present study, the potential drop over the plasma is therefore expected to be at least $800 \mathrm{~V}$, assuming a gap distance of $1 \mathrm{~mm}$. It follows that the plasma dissipates at least $3.2 \mathrm{~W}$. This is possible given the measurements of average power discussed previously. 
Revised manuscript to Journal of Physics D

\subsection{In situ Raman microspectrometer}

The Raman microspectrometer was built in-house, designed to suppress plasma emission and provide spectral imaging capability in one dimension. The latter goal was accomplished by asymmetric focusing of a laser beam to form a light sheet, which will be discussed in depth in the next section. The current apparatus is an improved version of the spectrometer used previously to track the synthesis of silicon nanocrystals by nanosecond discharges in air at atmospheric pressure (Pai et al. 2019).

As shown in Figure 2, a diode-pumped solid-state laser (Elforlight Spot) produced pulses at $532 \mathrm{~nm}$ of $2 \mathrm{~ns}$ duration at a repetition frequency of $30 \mathrm{kHz}$, with the average power measured to be $473 \mathrm{~mW}$. The beam first passed through an expander, followed by a variable power attenuator consisting of a rotating half-wave plate combined with a polarizing beamsplitter. A second half-wave plate rotated the laser polarization from vertical to horizontal. The beam underwent vertical focusing upon passing through a cylindrical lens (Figure 3). Upon reflection off a dichroic mirror (Semrock RazorEdge), the beam focused horizontally via a lens (focal length $75 \mathrm{~mm}$ ) or 50X microscope objective (Mitutoyo M Plan Apo, NA 0.55 and working distance 13 $\mathrm{mm})$. The lens performed visualization with a magnification of 2.7 and will henceforth be referred to as the "3X objective". Raman spectroscopy was performed using the 50X objective. The average laser power finally delivered to the target was $62 \mathrm{~mW}$. During in situ measurements, the laser was stable in power to within $3 \%$ with a jitter of $1 \mathrm{~ns}$, as measured by a power meter and photodiode placed behind the dichroic mirror.

The backscattered light was filtered through the dichroic mirror and then a notch filter (Semrock StopLine). A polarizer was aligned parallel to the horizontal polarization of the laser beam at the target. The parallel component of the Raman signal focused onto the entrance slit (width $50 \mu \mathrm{m}$ ) of a monochromator (Acton SP2500i, f/6.5 and focal length $0.5 \mathrm{~m}$ ) using an achromatic doublet lens (focal length $200 \mathrm{~mm}$ ) to achieve $3 \mathrm{X}$ and 50X magnifications. A grating with 600 grooves/mm dispersed light onto an intensified CCD camera (Princeton Instruments PIMAX 4) mounted at the exit plane of the monochromator. A delay generator (Stanford Research Systems DG645) synchronized the triggering of the camera gating and the laser. The camera gate duration was $30 \mathrm{~ns}$, which was long enough to fully capture the Raman signal yet short enough to suppress any detection of the optical emission from the plasma. The accumulations per exposure (6000) and exposures per frame (500) provided an acceptable tradeoff between the signal-to-noise 
Revised manuscript to Journal of Physics D

ratio and acquisition time (102 s per frame in real time). The $546 \mathrm{~nm}$ line of a mercury lamp (Princeton Instruments Intellical) served as the reference for measuring the instrumental function whose full-width half-maximum (FWHM) is $5.5 \mathrm{~cm}^{-1}$. This lamp was also used to perform wavelength calibration of the spectrometer. For calibration in relative intensity, a quartz tungsten halogen lamp (Newport QTH) served as the reference light source.

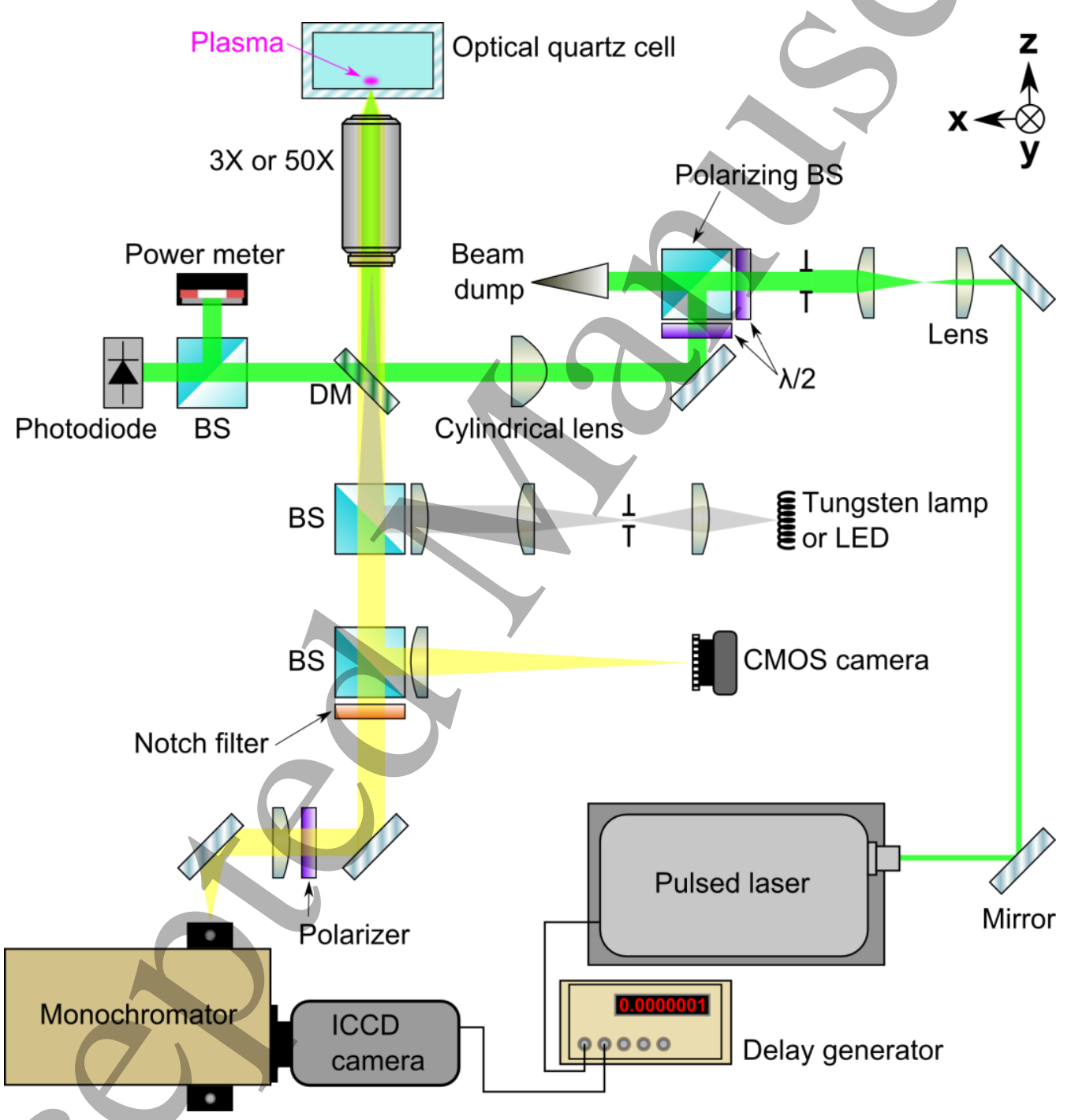

Figure 2: Top-view schematic diagram of the in situ Raman microspectrometer. The abbreviations are as follows: half-wave plates $(\lambda / 2)$, beamsplitters $(\mathrm{BS})$, dichroic mirror (DM). 
Revised manuscript to Journal of Physics D

\section{3. $\quad$ Light sheet}

As introduced in the previous section, asymmetric focusing of the laser beam was employed to enable spectral imaging in 1-D. The cylindrical lens and microscope objective together shaped the expanded laser beam into a light sheet (Ritter et al. 2011) that entered through the polished front face of the quartz cell (Figure 3), henceforth referred to as the "window". The cylindrical lens first focused the beam in the vertical $(y)$ plane at the rear focal plane of the 50X objective, which collimated the beam in $y$ (Figure 3(a)). The height of the semi-collimated beam is $\Delta y_{\text {las }} \approx 100 \mu \mathrm{m}$, which is discernible in Figure 3(b). In the horizontal $(x)$ plane, the collimated beam passed unaffected through the cylindrical lens and was focused subsequently by the objective (Figure 3(c)).

The position of the cell was adjusted using a micrometric translation stage along the laser axis $(z)$ such that the beam was focused at 50X on the rear surface of the window (Figure 3(c,d)). The beam waist $\left(2 w_{0}\right)$ measured at this location was $1.4 \mu \mathrm{m}$ (Supplementary Information). From the image in Figure 3(d), the Rayleigh range of the beam in the water $\left(z_{R}\right)$ is estimated to be about $400 \mu \mathrm{m}$ (Supplementary Information). The collected Raman signal of water (without plasma) was highest at this optimal position, weakening when focused instead inside the quartz or in the water. Most importantly, focusing on the rear surface was a consistent way to reproduce the same detection volume (DV) for each measurement.

Generating the plasma against the rear surface of the window brought the plasma-water interface into the DV, as shown in Figure 3(b). The imaging module of the Raman bench, as described in (Pai et al. 2019), was used to align the discharge with the light sheet (Figure 4(top,middle)). Lamp illumination clearly showed the plasma-water interface as well as the top of the meniscus. Video monitoring at $3 \mathrm{X}$ revealed that the plasma position in the $x$ direction varied in time by up to $200 \mu \mathrm{m}$, reflecting the power fluctuations observed in Figure 1 . In the $z$ direction, there was no noticeable change in focus of the plasma. Thus, the degree of movement of the plasma was small enough to keep the light sheet contained within the horizontal ( $x-z$ plane) bounds of the plasma interface. Also, the position of the plasma interface was much more stable in the $y$ direction, with no clear indication of unsteadiness. 
Revised manuscript to Journal of Physics D

(a)

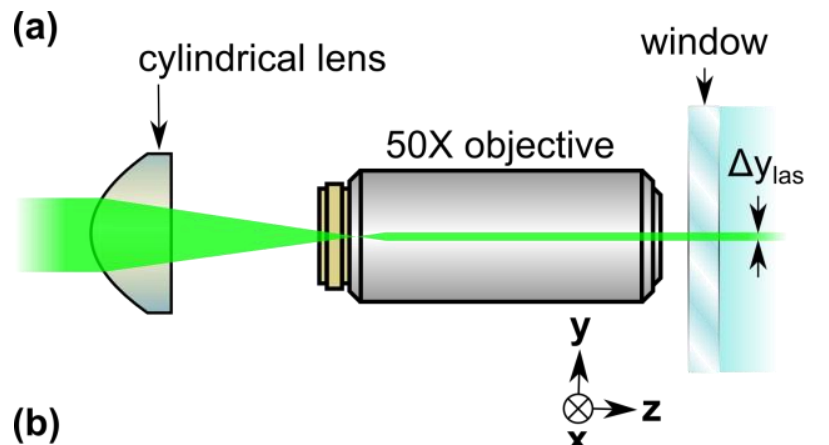

50X objective

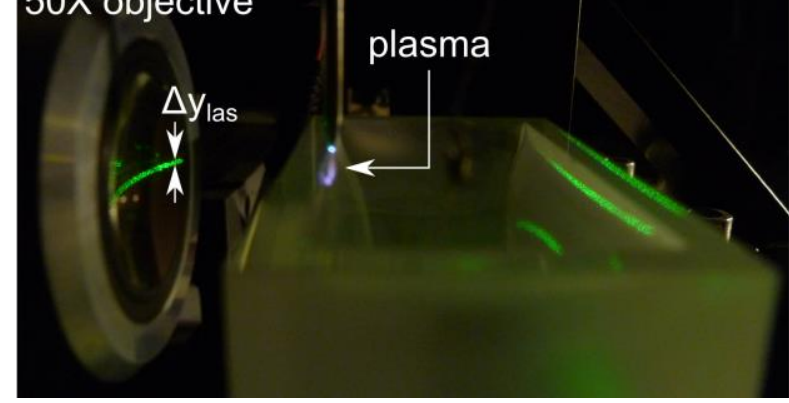

(c) cylindrical lens

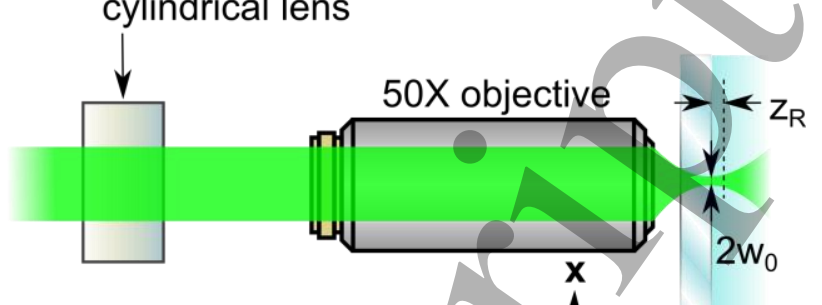

(d)

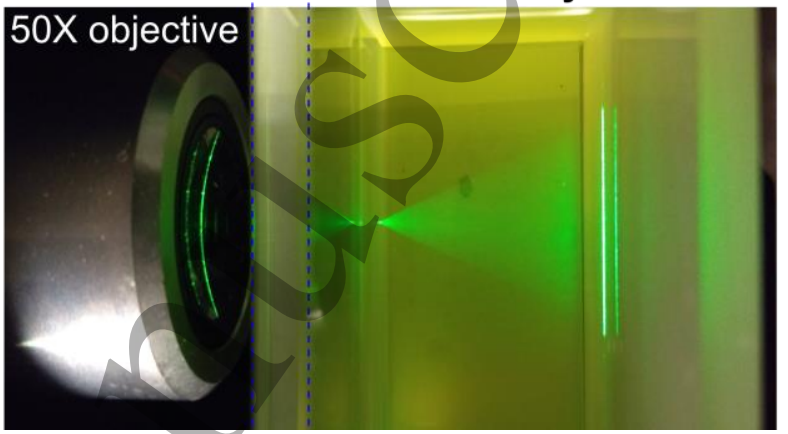

Figure 3: Schematic diagrams and images of light sheet formation at $50 \mathrm{X}$ by (a,b) collimation in the vertical direction and (c,d) focusing in the horizontal direction. The views of (a,b) and (c,d) are from the side and top, respectively. For the image (d), aqueous fluorescein solution renders the beam shape visible. 
Revised manuscript to Journal of Physics D
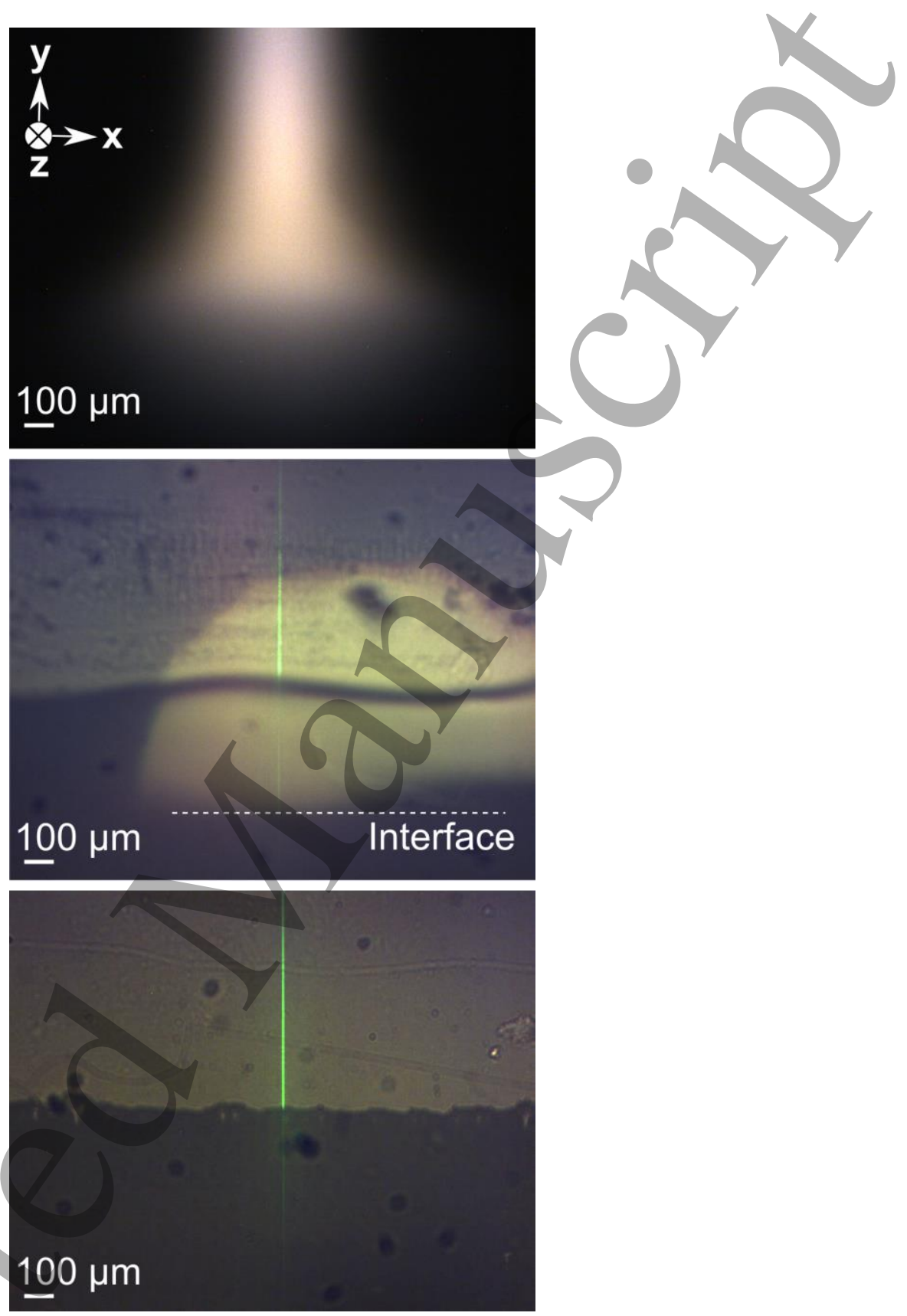

Figure 4: Images at $3 \mathrm{X}$ of (top) the plasma, (middle) the plasma-water interface, and (bottom) the meniscus of water never treated by plasma. These images are viewed by the microscope through the window of the quartz cell, with the focal plane positioned at the rear face of the window (Figure 3(c,d)). The vertical green line is the reflection of the light sheet from this surface. The bright semi-circle is the reflection of the lamp. 
Revised manuscript to Journal of Physics D

In this work, the signal strength of some of the Raman spectra was too low to make full use of the 1-D spectral imaging made possible by the light sheet. It was necessary to integrate over the detection volume to achieve a sufficient signal-to-noise ratio. Nevertheless, the light sheet ensured that the detection volume was precisely defined, clarifying the spatial information contained in the data, as will be demonstrated in the next section.

\subsection{Detection volume (DV)}

The dimensions of the detection volume (DV) at 50X were verified by scanning over a static meniscus of fresh water never treated by plasma (Figure 5(top)), whose image is shown in Figure 4(bottom). The spatial profile of laser intensity in $y$ mirrors the profile of Raman intensity when the light sheet is completely immersed in the water, i.e. when the fractional occupation of the DV by water $\left(f_{D V}\right)$ equals 1 . Acquiring this profile involves integrating the Raman intensity of the spectral image (Supplementary Information) of the $-\mathrm{OH}$ stretch band of water $(2800-3800$ $\mathrm{cm}^{-1}$ ) over the entire wavenumber range at each position in $y$. The profile for $f_{D V}=1$ smoothed by a Savitzky-Golay filter (black line, Figure 5(middle)) is used as the laser intensity profile I(ylas), where $y_{\text {las }}$ is the local vertical coordinate of the light sheet. The height of the light sheet at 50X is $\Delta y_{\text {las }}=96 \mu \mathrm{m}$.

The equation for the liquid-gas interface $y=\zeta(z)$ describes the shape of a static meniscus. The exact solution is given by (Batchelor and Batchelor 2000) p. 67 and traced in Figure 5(top):

$$
\frac{z}{l_{c}}=\cosh ^{-1} \frac{2 l_{c}}{\zeta}-\cosh ^{-1} \frac{2 l_{c}}{h}+\sqrt{4-\frac{h^{2}}{l_{c}^{2}}}-\sqrt{4-\frac{\zeta^{2}}{l_{c}^{2}}}
$$

where $l_{c}=\sqrt{\gamma / \rho g}=2.7 \mathrm{~mm}$ is the capillary length in terms of the mass density of water $(\rho=$ $\left.1000 \mathrm{~kg} / \mathrm{m}^{3}\right)$, the acceleration of gravity $\left(g=9.81 \mathrm{~m} / \mathrm{s}^{2}\right)$, and the surface tension of water at $20^{\circ} \mathrm{C}$ $(\gamma=0.073 \mathrm{~N} / \mathrm{m}$, from (Lide 1995)). The height of the liquid $(h)$ above the flat water level is defined by the contact line:

(2)

$$
h=\sqrt{2} l_{c}(1-\sin \theta)
$$


where $\theta$ is the contact angle of the water against glass. If a portion of the light sheet is above the flat water level at $y=0$, then the Raman intensity profile is determined by the overlap between the laser intensity profile $(I)$ and the thickness of the meniscus $(\Delta z)$ :

$$
\Delta z \cdot I=\zeta^{-1}(y) \cdot I\left(y_{\text {las }}=y-y_{\text {las }, 0}\right)
$$

where the bottom of the light sheet is found at $y=y_{l a s, 0}$. When the light sheet is fully immersed in the water, the value of $\Delta z$ is limited by the depth of field, assumed here to be the Rayleigh range $z_{R}=400 \mu \mathrm{m}$.

Figure 5(middle) shows Raman intensity profiles measured with the light sheet positioned at different heights $y_{l a s, 0}$ that scan the static meniscus. To vary $y_{l a s, 0}$, water was added or removed from the quartz cell. As $y_{l a s, 0}$ increases, $f_{D V}$ diminishes from 1 down to 0.039 , according to the total Raman intensity. Corresponding profiles are modeled using equations (1)-(3) to match simultaneously $f_{D V}$ from experiment and the intensity profiles, as shown by the solid lines in Figure 5 (middle). For fresh water untreated by plasma, the contact angle of water against glass is $\theta=45^{\circ}$ (Yamamoto et al. 2004), and this is the value assumed in the modeled profiles. Exposure to plasma increases hydrophilicity to glass, resulting in a decrease in the value of $\theta$ relative to fresh water. This is reflected in Figure 5(bottom), which shows the case of water after plasma treatment, where $\theta=\pi / 7$ is chosen to fit the model to the measured profiles. 
Revised manuscript to Journal of Physics D
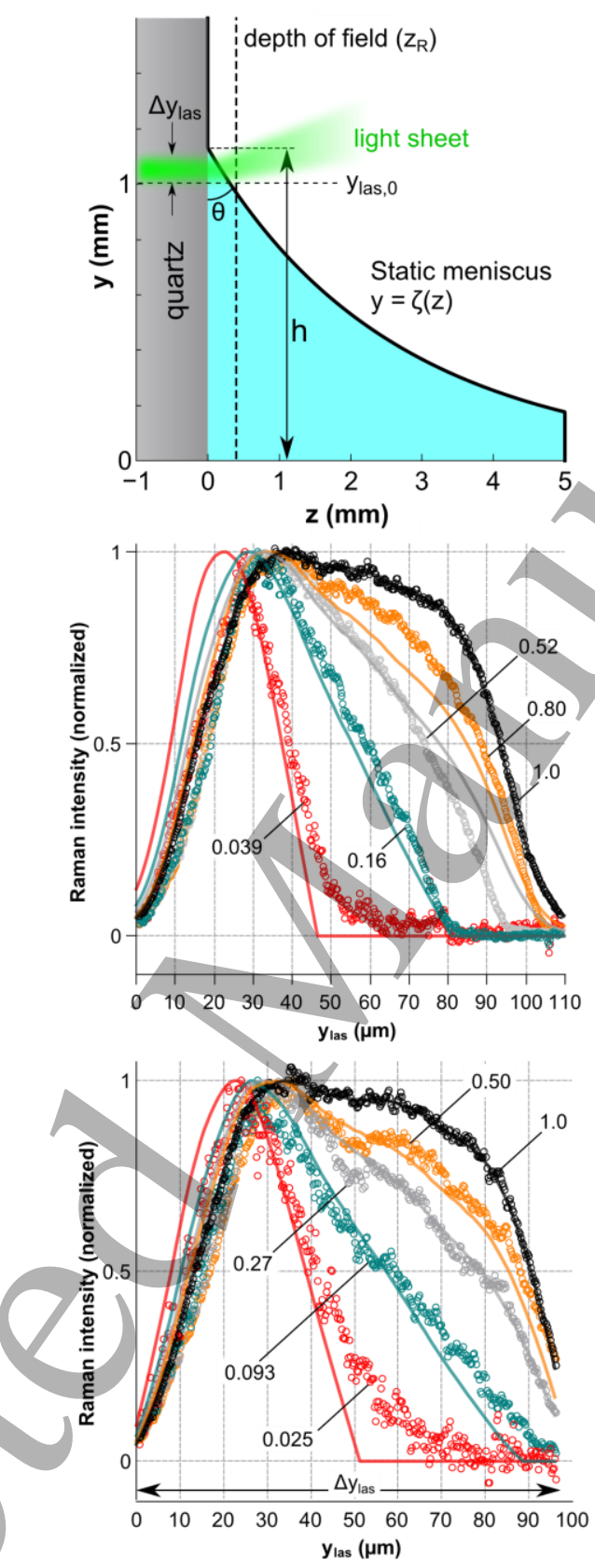

Figure 5: Static meniscus of water without plasma: (top) shape of the water surface calculated using equations (1) and (2) with $\theta=45^{\circ}$ corresponding to fresh water, (middle) measured (symbols) and modeled (equation (3) with $\theta=45^{\circ}$, lines) vertical profiles at $50 \mathrm{X}$ of the integrated Raman intensity of the - $\mathrm{OH}$ stretch band of fresh water for several values of $f_{D V}$, and (bottom) similarly measured (symbols) profiles of water after plasma treatment, where $\theta=\pi / 7$ is assumed for the modeled profiles (lines). 
Revised manuscript to Journal of Physics D

Acceptable agreement between model and experiment is found down to $f_{D V}=0.025$, with discrepancies attributable to a tilt of the quartz cell in the $y$ - $z$ plane, which could cause slight distortions of the meniscus shape as well as off-normal incidence of the laser sheet on the window. This demonstrates that the model of a collimated light sheet described by $I\left(y_{\text {las }}\right)$ along with a depth of field of $z_{R}=400 \mu \mathrm{m}$ is appropriate and can handle a curved water surface such as a meniscus. A final consideration is the lateral $(x)$ span of Raman scattering, which is limited by the spatial filtering by the entrance slit of the monochromator. At 50X, this means that a $50-\mu \mathrm{m}$ wide slit allows through an image with length $\Delta x=1 \mu \mathrm{m}$. The DV is thus defined by a rectangular prism with a volume of $38 \mathrm{pL}\left(\Delta y_{\text {las }}=96 \mu \mathrm{m}, \Delta z=400 \mu \mathrm{m}\right.$, and $\left.\Delta x=1 \mu \mathrm{m}\right)$.

\section{Results}

\subsection{In situ Raman tracking}

Figure 6 shows the spectral domain used throughout this study. Three Raman modes are identifiable: -OO stretch of $\mathrm{H}_{2} \mathrm{O}_{2}$ at $880 \mathrm{~cm}^{-1}$, symmetric stretch $\left(v_{1}\right)$ of $\mathrm{NO}_{3}{ }^{-}$at $1052 \mathrm{~cm}^{-1}$, and $\mathrm{OH}$ bend of water at $1637 \mathrm{~cm}^{-1}$. The continuum baseline due to the Raman librational band of water is subtracted from the calibrated spectrum. No single correction algorithm has been found to provide a satisfactorily flat baseline across the entire spectral domain. Therefore, the domain is divided into two parts that are processed separately. In the $1000-1800 \mathrm{~cm}^{-1}$ range, the adaptive iteratively reweighted penalized least squares algorithm (Zhang et al. 2010) provides the best correction, whereas a modified least-squares polynomial curve fitting method (Lieber and Mahadevan-Jansen 2003) works best in the $800-1200 \mathrm{~cm}^{-1}$ range.

Following baseline correction, the spectra are fitted according to a least-squares optimization routine by four Gaussian functions, along with convolution with the instrumental function. In the $1000-1800 \mathrm{~cm}^{-1}$ range, two Gaussians fit the $-\mathrm{OH}$ bend band, one Gaussian fits the $\mathrm{NO}_{3}{ }^{-}$peak, and one Gaussian fits any residual baseline features. In the $800-1200 \mathrm{~cm}^{-1}$ range, single Gaussians fit the $\mathrm{NO}_{3}$ and $\mathrm{H}_{2} \mathrm{O}_{2}$ peaks, and two Gaussians fit the residual baseline. From these fits, the FWHM of each deconvoluted Raman peak is computed for each acquired spectrum. 
Revised manuscript to Journal of Physics D

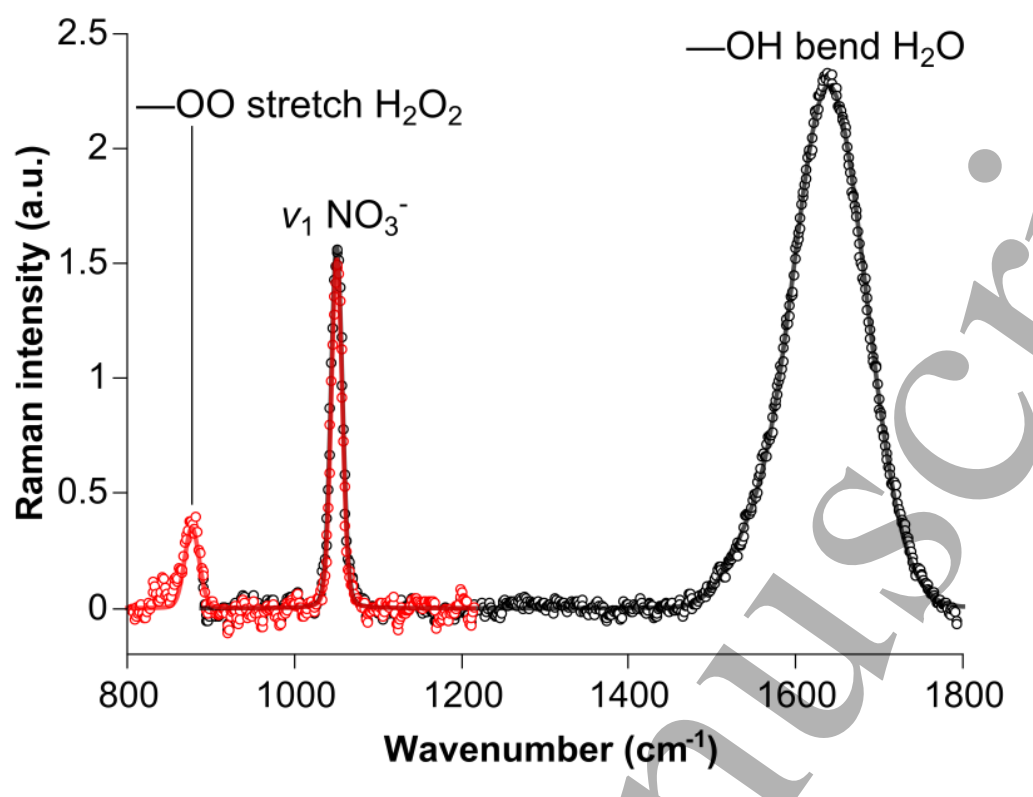

Figure 6: In situ Raman spectrum after different baseline subtraction algorithms applied in the $800-1200 \mathrm{~cm}^{-1}$ (red) and $1000-1800 \mathrm{~cm}^{-1}$ (black) ranges, as described above, with the measurement (symbols) fitted by Gaussian lineshapes (lines). This spectrum was acquired at 428 minutes of plasma treatment.

The interface comes into view when the Raman intensity of $-\mathrm{OH}$ bend begins to decrease, which is equivalent to a proportional decrease in the volume of water under detection. This volume can be expressed as the fraction $f_{D V}$ of $\mathrm{DV}=38 \mathrm{pL}$. At $f_{D V}=1$, the acquired Raman spectrum represents the spatial average of the top $96 \mu \mathrm{m}$-thick layer of water. Given the shape of the DV determined in section 2.4, and the flat shape of the plasma interface observable in Figure 4(middle), it is assumed that decreasing $f_{D V}$ is equivalent to decreasing the water level and therefore the depth of the surface layer under observation. The water level decreases naturally during plasma treatment through evaporation, causing $f_{D V}$ to decrease. Adding fresh water via micropipette or "dosing" at the beginning of each acquisition served to either slow this descent or elevate the water level. Occasionally, water was removed to obtain a rapid descent.

Modulating $f_{D V}$ in real time during plasma treatment revealed differences between the chemistry of the bulk and interfacial regions. Figure 7 shows the evolution of the liquid chemistry over 277 minutes of plasma treatment, starting from untreated ultrapure water. The $f_{D V}$ cycled four times between 1 down to values as low as 0.09 , each time with a different dosing history (Supplementary Information). The data analysis presented in Figure 7 is based on spectra 
Revised manuscript to Journal of Physics D

comprised of sliding averages of 10 frames. Doing so improves the quality of the spectral fits without sacrificing useful time resolution, because the dynamics of the chemistry is slow. The $f_{D V}$ equals the integrated intensity of the $-\mathrm{OH}$ bend band, normalized to its maximum value (Figure $7(\mathrm{a}))$.
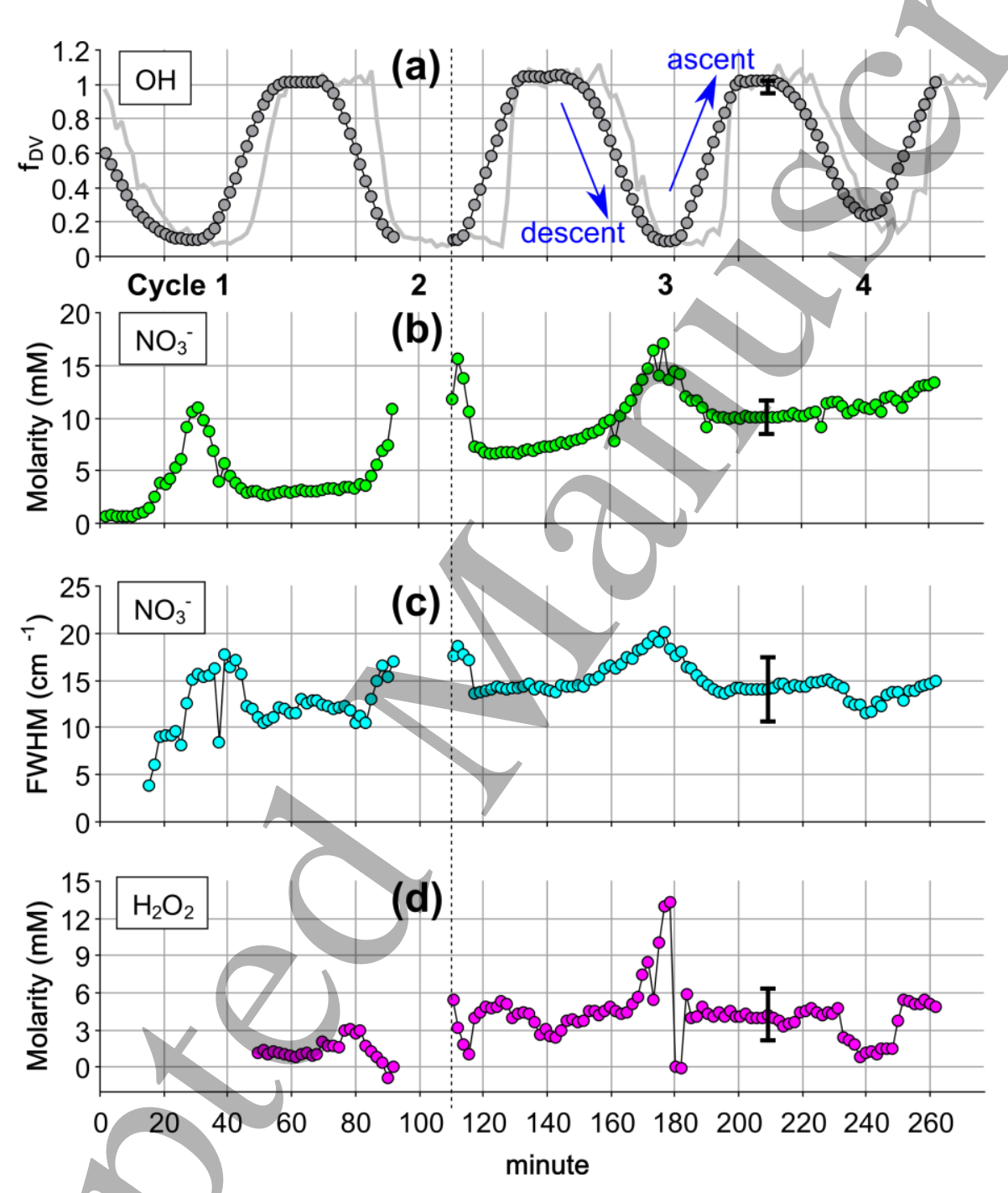

Figure 7: In situ Raman measurements as a function of time during plasma operation: (a) fractional occupation $\left(f_{D V}\right)$ of the $\mathrm{DV}$ measured by the integrated intensity of the -OH bend mode of water, (b) molarity of $\mathrm{NO}^{-}$calculated from the integrated intensity of the $v_{1}$ mode and (c) its FWHM, and (d) molarity of $\mathrm{H}_{2} \mathrm{O}_{2}$ calculated from the integrated intensity of the -OO stretch mode. All the data points shown are values based a sliding average of ten frames (symbols), except for single-frame values in (a) for $f_{D V}$ (line). Vertical dashes demarcate a pause of a few minutes in the Raman measurements while the plasma operated continuously. 

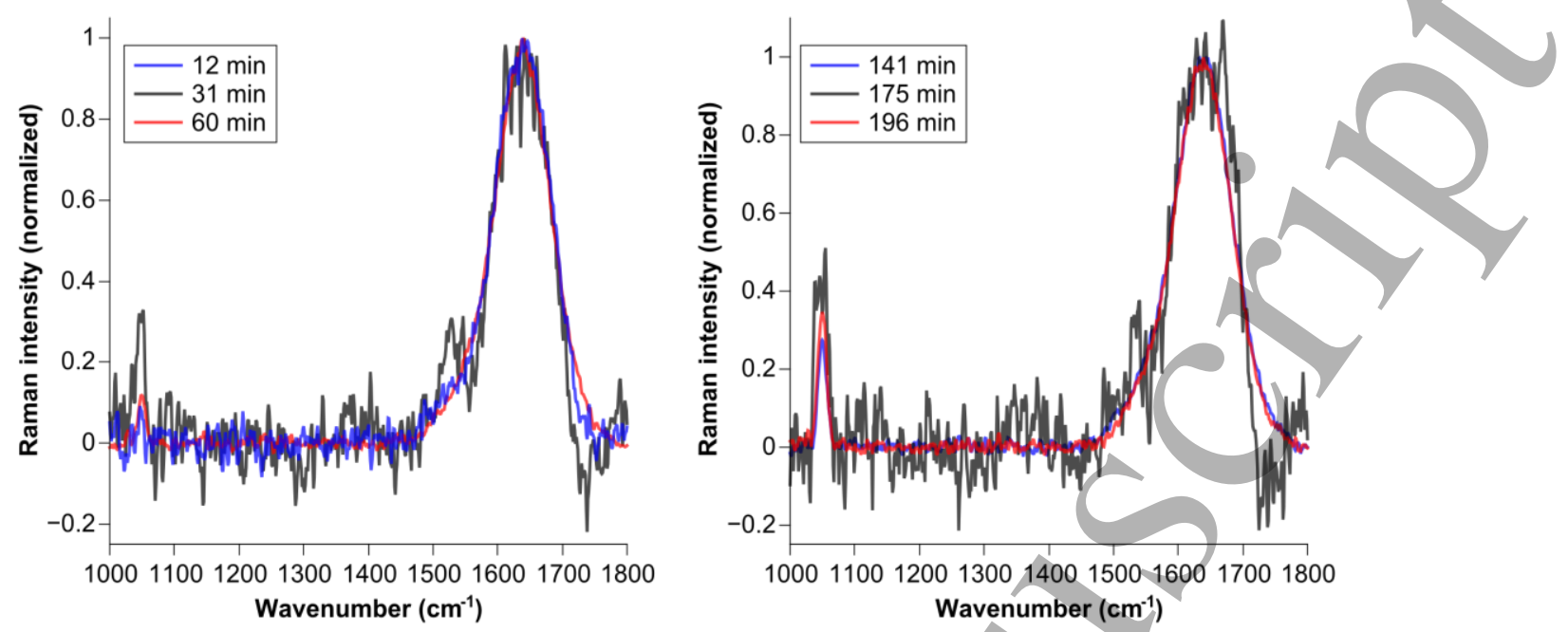

Figure 8: Sliding-average spectra from Figure 7 at selected times before and after $f_{D V}$ modulation, as well as near the minimum $f_{D V}$, for cycle 1 (left) and cycle 3 (right).

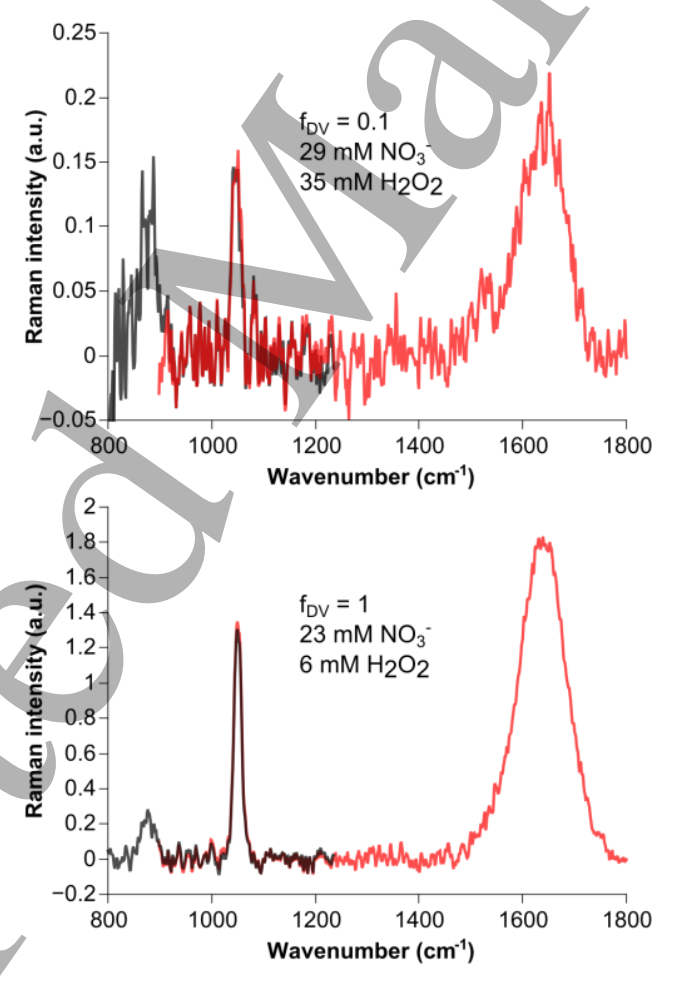

Figure 9: Comparison of spectra obtain at low (top) and high (bottom) volumes of water under detection during a different experimental run from Figure 7 and Figure 8. The spectrum at $f_{D V}=1$ was acquired 41 minutes after that at $f_{D V}=0.1$. The sliding average is across 5 acquisitions in this case. Separate baseline subtraction algorithms (black, red) have been applied to two sections of each spectrum, as shown in Figure 6. 
Revised manuscript to Journal of Physics D

The ratio of the integrated intensities of the $\mathrm{NO}_{3}{ }^{-} v_{1}$ band to the $-\mathrm{OH}$ bend band of water is assigned to the molar concentration of the nitrate anion, based on a calibration curve constructed from Raman measurements of stock solutions of nitric acid. The calibration curve is linear as a function of nitric acid concentration over the range of $\mathrm{NO}_{3}{ }^{-}$concentrations of interest in this work, with a root-mean square error (RMSE) of $1 \mathrm{mM}$. Figure 7(b) shows that the concentration reaches the detection threshold of $1 \mathrm{mM}$ at $12 \mathrm{~min}$ and follows an underlying linear progression with time regardless of $f_{D V}$, reaching a final value of $20 \mathrm{mM}$ after $428 \mathrm{~min}$ of plasma operation (not shown). The underlying linear growth rate is $48 \mu \mathrm{M} / \mathrm{min}$, which is clear when $f_{D V}$ is high. The underlying value of the FWHM of the $v_{1}$ band, which is clearly observed at high $f_{D V}$, increases slowly before stabilizing at around $120 \mathrm{~min}$ at a value of $14.4 \pm 0.3 \mathrm{~cm}^{-1}$ (Figure 7(c)).

The ratio of the integrated intensities of the $-\mathrm{OO}$ stretch band of $\mathrm{H}_{2} \mathrm{O}_{2}$ to the $-\mathrm{OH}$ bend band of water is assigned to the molar concentration of hydrogen peroxide, based on a calibration curve constructed using stock solutions of $\mathrm{H}_{2} \mathrm{O}_{2}$ with $\mathrm{RMSE} \approx 1 \mathrm{mM}$. Figure 7(d) shows that the $\mathrm{H}_{2} \mathrm{O}_{2}$ concentration rises above the detection threshold of $1 \mathrm{mM}$ at about $49 \mathrm{~min}$. The underlying concentration appears to plateau at around $4 \mathrm{mM}$ by $200 \mathrm{~min}$ but continues to rise unsteadily afterwards, eventually reaching a final value of $5 \mathrm{mM}$ after $428 \mathrm{~min}$ of plasma operation (not shown). The overall average growth rate is $11 \mu \mathrm{M} / \mathrm{min}$.

The uncertainties of each measurement shown in Figure 9 are indicated by representative error bars at $209 \mathrm{~min}$. Each data point represents a rolling average of 10 frames, except for the single-frame data for $f_{D V}$ presented as a solid line in Figure 9(a). Thus, for each measured quantity, one source of uncertainty is the standard deviation of single-frame measurements, calculated using the ensemble of data points at high $f_{D V}$. These standard deviations are $0.034,1.3 \mathrm{mM}, 3.4 \mathrm{~cm}^{-1}$, and $1.9 \mathrm{mM}$ for $f_{D V}$, the $\mathrm{NO}_{3}{ }^{-}$concentration, the FWHM of $\mathrm{NO}_{3}^{-}$, and the $\mathrm{H}_{2} \mathrm{O}_{2}$ concentration, respectively. For $f_{D V}$ and the $\mathrm{FWHM}$ of $\mathrm{NO}_{3}{ }^{-}$no additional uncertainty is considered. For the $\mathrm{NO}_{3}{ }^{-}$ and $\mathrm{H}_{2} \mathrm{O}_{2}$ concentrations, the RMSE of the calibration curves was also included, yielding uncertainties of 1.6 and $2.1 \mathrm{mM}$, respectively. Note that the procedure described previously for baseline correction and lineshape fitting is applied separately to single-frame and rolling-average experimental spectra. A rolling-average data point is not simply the numerical average of 10 single-frame data points. Instead, ten single-frame spectra are first averaged together, and then the baseline correction and lineshape fitting are applied to determine the data points. 


\section{Revised manuscript to Journal of Physics D}

Important deviations from these underlying trends occur when $f_{D V}<0.2$. The concentration and FWHM of $\mathrm{NO}_{3}{ }^{-}$predominantly increase when probing this close to the interface. Spurious decreases can also occur due to dosing, an issue to be addressed shortly. Despite the diminished signal-to-noise ratio at low $f_{D V}$, direct comparison of the spectra at different times before, during, and after a given cycle demonstrates that increases in the concentration and FWHM of $\mathrm{NO}_{3}{ }^{-}$at the minimum $f_{D V}$ are both unambiguous (Figure 8). The goodness of the Gaussian fits suffers somewhat at low $f_{D V}$, but the calculated FWHM shown in Figure 7(c) still faithfully reflects the experimental spectra (Supplementary Information). These departures from the underlying trends occur only at low $f_{D V}$, showing that the chemistry of the interfacial region is distinct from that of the bulk liquid, whose characteristics remain stable as long as $f_{D V}>0.2$. If the change in fractional occupation is only due to a change in depth, then $f_{D V}=0.2$ implies that the interfacial region of $\mathrm{NO}_{3}{ }^{-}$is $20 \mu \mathrm{m}$ deep.

The $\mathrm{H}_{2} \mathrm{O}_{2}$ concentration also increases at low $f_{D V}$. However, the signal-to-noise ratio is worse than for $\mathrm{NO}_{3}{ }^{-}$, and the error in the concentration at these times was significant for the experiment shown in Figure 7(d). However, repeated experiments that produced higher quality spectra for $\mathrm{H}_{2} \mathrm{O}_{2}$ have reproduced this result. For example, Figure 9 shows an acquisition from a different experiment in which the spectrum of $\mathrm{H}_{2} \mathrm{O}_{2}$ at $f_{D V}=0.1$ is relatively well defined. The corresponding concentration is $35 \mathrm{mM}$, which is considerably higher than the peak value obtained in Figure 7(d). When $f_{D V}=1$ for spectrum acquired 41 min later in real time while continuously operating the plasma, the intensities of both $\mathrm{H}_{2} \mathrm{O}_{2}$ and $\mathrm{NO}_{3}{ }^{-}$are lower relative to that of $-\mathrm{OH}$ bend. The corresponding concentration of $\mathrm{H}_{2} \mathrm{O}_{2}$ is $6 \mathrm{mM}$, found in the bulk liquid.

Consider now the details related to each cycle of $f_{D V}$ modulation. Phases of "descent" or “ascent" will refer to periods during which $f_{D V}$ decreased or increased, respectively (Figure 7(a)). The descent phase of cycle 1 involved active modulation, where dosing served to slow the descent (see Supplementary Information). For cycle 2, the opposite approach was taken: water removal during several acquisitions produced a rapid descent. During cycles 3 and 4, the water level descended naturally by evaporation. The model cases are thus the descent phases of cycles 3 and 4, during which passive modulation avoided any undue perturbation by dosing.

During cycle $3, f_{D V}$ reaches a minimum value of 0.09 , at which point the $\mathrm{NO}_{3}{ }^{-}$concentration increases sharply up to $17 \mathrm{mM}$ at $177 \mathrm{~min}$, which is well above the underlying bulk liquid value of $9-10 \mathrm{mM}$. At the same time, the FWHM of the $\mathrm{NO}_{3}{ }^{-} v_{1}$ band increases up to $21 \mathrm{~cm}^{-1}$. Figure 
8(right) confirms that the $v_{1}$ band is both broader and more intense at $177 \mathrm{~min}$ than before and after cycle 3 . The $\mathrm{H}_{2} \mathrm{O}_{2}$ concentration simultaneously increases from its underlying value of $4 \mathrm{mM}$ up to $13 \mathrm{mM}$ before abruptly decreasing to zero at $180 \mathrm{~min}$, which coincides with the moment when dosing resumes to begin the ascent phase (Supplementary Information). By $185 \mathrm{~min}$, the $\mathrm{H}_{2} \mathrm{O}_{2}$ concentration has recovered back up to $4 \mathrm{mM}$ and remains steady for the rest of cycle 3 . This indicates that dosing may introduce spurious effects into the measurement.

During the descent phase of cycle $4, f_{D V}$ only reached a minimum of 0.24 , which is not enough to observe the interfacial layer as clearly as when $f_{D V}<0.2$ is achieved (cycles 1-3). The $\mathrm{NO}_{3}{ }^{-}$concentration experiences minimal perturbation from its bulk liquid behavior. The necessity of reaching low $f_{D V}$ to observe large increases in nitrate will become evident upon constructing the depth profile in section 3.2. However, from 233 to 248 min the $\mathrm{H}_{2} \mathrm{O}_{2}$ concentration decreases from 5 to $1 \mathrm{mM}$, once again when dosing resumes to begin the ascent phase. Meanwhile, the $\mathrm{NO}_{3}{ }^{-}\left(v_{1}\right)$ peak narrows somewhat, rather than broadening as in cycle 3. Thus, in cycle 4 the decrease in $\mathrm{H}_{2} \mathrm{O}_{2}$ molarity is not accompanied by a decrease in nitrate molarity. This suggests that nitrate recovers much faster from a disturbance by dosing than does $\mathrm{H}_{2} \mathrm{O}_{2}$.

There was no means to control the flow in the cell to prevent dosed water from intruding into the interfacial zone. Thus, fresh water may enter the DV, diluting species or otherwise altering the state of the water. However, dosing when $f_{D V}>0.2$ causes little disturbance, although the $\mathrm{H}_{2} \mathrm{O}_{2}$ concentration can be affected near this threshold, as just discussed above. Even dosing when $f_{D V}<$ 0.2 usually does not affect the essential results. This is true for the descent phases of cycles 1 and 2, when the $\mathrm{NO}_{3}{ }^{-}$concentration and FWHM follow the same trends as the descent phases of cycles 3 and 4 . The effect of dosing on cycles 1 and 2 becomes apparent upon closer examination, which will be discussed shortly.

However, if $f_{D V}$ decreases down to 0.05 , then major deviations can occur while dosing (not shown). The $\mathrm{NO}_{3}$ concentration can either diminish or increase relative to the underlying bulk liquid, while the $\mathrm{H}_{2} \mathrm{O}_{2}$ concentration still increases. At $f_{D V}=0.05$, the top layer of water under observation is in principle only $5 \mu \mathrm{m}$ deep. The chemistry here may differ from when $f_{D V}=0.2$. On the other hand, such a shallow layer may also be more sensitive to perturbations from dosing. Also, $f_{D V}=0.05$ is close to the detection limit determined in Figure 5 . 
Revised manuscript to Journal of Physics D

\subsection{Structure of the interfacial region}

It is now possible to construct the depth profile of excess $\mathrm{NO}_{3}{ }^{-}$concentration (relative to the bulk liquid) in the interfacial region. Let $c(y, t)=c_{B}(t)+c_{S}(y)$ be the total concentration at time $t$ as a function of the depth $y$ below the surface, where $c_{B}$ is the spatially uniform bulk liquid concentration. The excess surface concentration $c_{S}$ is assumed to remain constant in time at a given location, which is justified because the $\mathrm{NO}_{3}{ }^{-}$concentration responds to $f_{D \eta}$ modulation in a consistent way during cycles 1-3 (Figure 7(b)). Let $L=f_{D V} \times \Delta y_{\text {las }}$ be the depth of the water volume contained in the DV. Then the measured concentration $\left(c_{a v}\right)$ represents the total concentration at time $t$ averaged spatially from the surface at $y=0$ down to $y=-\mathcal{L}$ :

$$
c_{a v}(L, t)=c_{B}(t)+\frac{1}{L} \int_{-L}^{0} c_{S}(y) d y
$$

Figure 10(top) shows $c_{a v}$ plotted as a function of $L$ for the acquisitions obtained during the descent phase of cycle 3. Let $c_{S, a v}=c_{a v}-c_{B}$ be the spatially averaged profile of excess concentration. Differentiating equation (4) to reconstruct the spatially resolved depth profile of excess concentration $(c s)$ yields:

$$
c_{S}(y=-L)=\frac{d}{d L}\left(c_{S, a v} L\right)=c_{S, a v}+L \frac{d}{d L} c_{S, a v}
$$

For smooth differentiation, equation (5) can be evaluated using a fitting function $c_{S, a v}=a /\left(1+b L^{c}\right)$ shown in Figure 10(top). The depth of the interfacial region is $28 \mu \mathrm{m}$, where the boundary is defined here by $c_{S}=0$. At $y<-28 \mu \mathrm{m}, c_{S}$ becomes slightly negative, implying a deficit of $\mathrm{NO}_{3}{ }^{-}$ concentration relative to the bulk liquid instead of an excess.

To understand this, consider the hypothetical case where all of the $\mathrm{NO}_{3}{ }^{-}$is found within a depth shallower than the smallest $L$ measured, i.e. at $y<9 \mu \mathrm{m}$. In this case, increasing $L$ amounts to the virtual dilution of $\mathrm{NO}_{3}{ }^{-}$, in other words $c_{S, a v}(L>9)=c_{S, a v}(L=9) \times(9 / L)$ where $L$ is expressed in $\mu \mathrm{m}$. If the measured $c_{S, a v}$ diminishes faster with $L$ than the curve of virtual dilution, then $c_{S}$ becomes negative (Supplementary Information). Given that virtual dilution assumes zero 
excess $\mathrm{NO}_{3}{ }^{-}$concentration at $L>9 \mu \mathrm{m}$, the only way to obtain $c_{S}<0$ is to diminish $c_{S, a v}$ at $L<9 \mu \mathrm{m}$. In other words, physical dilution must occur at a depth unresolved by the measurement.
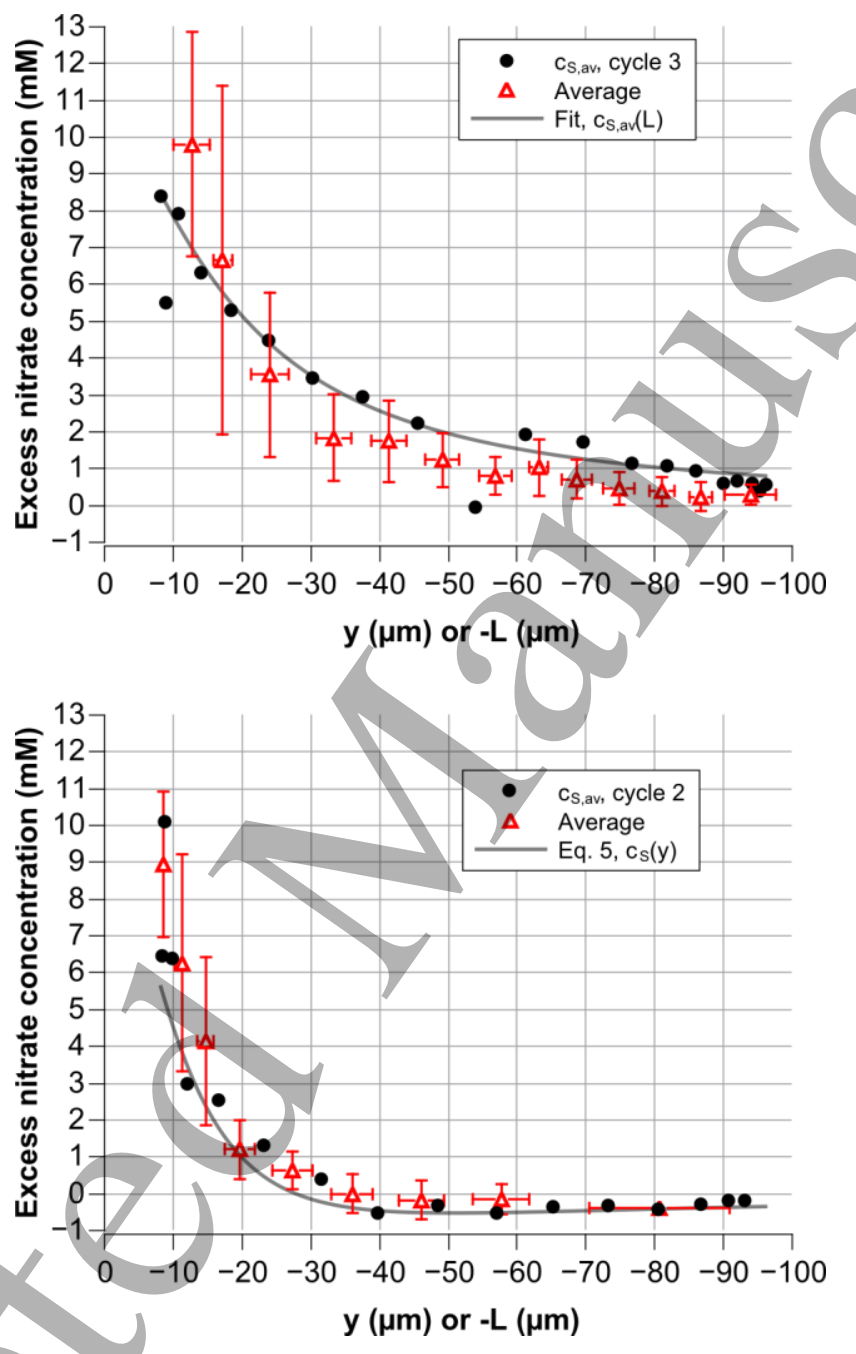

Figure 10: Spatially averaged excess concentration $\left(c_{S, a v}\right)$ of $\mathrm{NO}_{3}^{-}$as a function of the depth ( $L$ ) of the water volume contained in the DV (top), for the descent phase of cycle 3 from Figure 7(b) as well as averaged over several experiments without dosing. Also shown is the fit to the data used to calculate the spatially-resolved excess concentration $\left(c_{S}\right)$ presented in (bottom), which is compared to $c_{S, a v}$ for the descent phase of cycle 2 from Figure 7(b) as well as averaged over several experiments with dosing. The error bars signify the standard deviations in $y$ and excess $\mathrm{NO}^{-}$concentration for each set of ten data points averaged together. 


\section{Revised manuscript to Journal of Physics D}

There is no reason for such a top-layer dilution to occur during cycle 3 , since no water dosing occurred. A small error in the data or its fitting can explain the small negative values of $c s$. However, cycles 1 and 2 did involve dosing, and their $c_{S, a v}$ curves indeed decrease much faster with $L$ than the curve of virtual dilution (Supplementary Information). Furthermore, the $c_{S \text {, av }}$ curve of cycle 2 matches the $c_{S}$ curve of cycle 3 (Figure 10(bottom)). This is possible if the excess $\mathrm{NO}_{3}{ }^{-}$ concentration is zero at $L<9 \mu \mathrm{m}$. Such a situation may occur because dosing was applied at the beginning of each acquisition during cycles 1 and 2, as well as in the other experiments averaged together in Figure 10(bottom), providing the opportunity for newly introduced water to displace PAW at the top surface layer.

Figure 10 also presents the values and standard deviations of $c_{S, a v}$ averaged over several experiments. The statistical analysis extends over 5 and 8 individual cycles without and with dosing, respectively, including the experiment presented in Figure 7. The uncertainty reflects variations between each experiment as well as changes in optical alignment. In particular, the latter is responsible for lowering the average below the curve for cycle 3 of Figure 10(top) in parts of the $y$ range, probably because of the tilt of the quartz cell discussed in section 2.4. The error bars for average $c_{S, a v}$ with and without dosing do not overlap at all for $y \leq-24 \mu \mathrm{m}$, demonstrating that the change to the depth profile due to dosing is statistically significant.

The meniscus created by the plasma must be considered when interpreting the depth profile of Figure 10. Judging from the image shown in Figure 4(middle) at 3X magnification, the structure of the plasma-on meniscus may resemble the shape observed for a meniscus driven by Marangoni stress (Fanton et al. 1996). In such a case, a curved base section similar to a static meniscus leads up to a vertical thin film, followed by a ridge of thickened liquid at the top. The $50-\mu \mathrm{m}$ dark band horizontally traversing the field of view in Figure 4(middle) and the semi-transparent region directly underneath may be identified as the ridge and thin film, respectively.

Figure 11 presents the meniscus when viewed at 50X during plasma operation, along with corresponding images of the meniscus formed before switching on the plasma. Simultaneous Raman spectra of the $-\mathrm{OH}$ stretch band were acquired, from which $f_{D V}$ could be calculated. Like at $3 \mathrm{X}$ (Figure 4(bottom)), the meniscus with the plasma off either weakly reflects the laser and lamp light when the laser sheet is well submerged $\left(f_{D V} \geq 0.24\right)$ or strongly reflects both light sources when the laser sheet intersects the top of the meniscus $\left(f_{D V}=0.04\right)$. At $f_{D V}=0.12$, it is possible to observe/an uneven transition between these two modes of light reflection. When the plasma is 
switched on, both the laser and lamp similarly reflect weakly at $f_{D V} \geq 0.52$. An addition background illumination originates from plasma light emission scattered from above the interface. At $f_{D V} \leq$ 0.36, the meniscus causes the strong reflection only of the lamp light, as observed in Figure 4(middle).

The detection volume likely enters the plasma-on meniscus between $f_{D V}=0.36$ and 0.52 . Yet the excess $\mathrm{NO}_{3}{ }^{-}$concentration commences its increase at higher $f_{D V}$ (Figure 7(b)), which is also apparent when comparing the depth profiles with and without dosing (Figure 10). It follows that excess $\mathrm{NO}_{3}{ }^{-}$is found in the liquid near the curved base of the meniscus joining the bulk liquid. Therefore, despite the complex shape of the interface due to the plasma meniscus, the spatially averaged excess concentration $\left(c_{S, a v}\right)$ of $\mathrm{NO}_{3}{ }^{-}$still reflects a depth profile near the plasma interface best represented by the spatially-resolved excess concentration $\left(c_{S}\right)$, given the knowledge at hand.

It is possible for a thin film section of the meniscus to distort the depth profile because the plasma interface becomes vertical in this case rather than horizontal. Very low values of $f_{D V}$ may then indicate that the film thickness rather than the Rayleigh range limits detection in the $z$ direction. For example, for $f_{D V}=0.04$ with the plasma on in Figure 11(bottom), the film thickness would be $0.04 \times z_{R}=16 \mu \mathrm{m}$ assuming a vertical, uniformly flat film covering the entire field of view. In this situation, the laser sheet encounters the water-air interface of the film. As a result, the 
Revised manuscript to Journal of Physics D

laser diffraction pattern fluctuates in time, reflecting variations in the thickness of the thin film. On the other hand, at $f_{D V} \geq 0.24$, the laser diffraction pattern remains stable at all times, indicating the observation of the thicker curved base of the meniscus.

If Figure 11 indeed reflects a complex, curved surface entering the field of view, then the one-dimensional treatment of the depth profile assumed by $L=f_{D V} \times \Delta y_{\text {las }}$ for equations (4) and (5) must be treated as a simplification. The depth profiles shown in Figure 10 must then be considered approximate without further information on the exact shape of the meniscus created by the plasma.

\section{Discussion}

The following two sections concern the comparison of the results from section 3 on the bulk liquid and the interface regions to previous experimental and modeling studies. The discussion in section 4.1 benefits from a relatively large body of literature on the bulk liquid chemistry of glow discharges generated in contact with water. The analysis in section 4.2 relies more on investigations of other types of plasma sources because fewer works have considered the plasma-water interface of DC glow discharges.

\subsection{Bulk liquid-phase chemistry}

The following is a brief overview of the aspects of bulk liquid chemistry relevant to the results from section 3.1. For a DC glow discharge in ambient air with an aqueous solution of $\mathrm{NaCl}$ as the cathode, (He et al. 2017) performed UV-VIS absorption of aqueous species in real time, though outside the reactor. Like the present work (Figure 7), they reported that the $\mathrm{NO}_{3}{ }^{-}$ concentration increases faster than that of $\mathrm{H}_{2} \mathrm{O}_{2}$. Also, they observed that both $\mathrm{NO}_{2}^{-}$and $\mathrm{H}_{2} \mathrm{O}_{2}$ concentrations increase first for several minutes before declining at the same time that the $\mathrm{NO}_{3}{ }^{-}$ concentration begins to increase. This supports the following mechanism governing the concentrations of aqueous $\mathrm{NO}_{2}{ }^{-}, \mathrm{NO}_{3}{ }^{-}$, and $\mathrm{H}_{2} \mathrm{O}_{2}$ (Lukes et al. 2014):

(R1)

(R2)

$$
\begin{gathered}
\mathrm{H}_{2} \mathrm{O}_{2}+\mathrm{NO}_{2}^{-}+\mathrm{H}^{+} \rightarrow \mathrm{ONOOH}+\mathrm{H}_{2} \mathrm{O} \\
\mathrm{ONOOH} \rightarrow \mathrm{HNO}_{3} \rightarrow \mathrm{H}^{+}+\mathrm{NO}_{3}^{-}
\end{gathered}
$$


Revised manuscript to Journal of Physics D

A closely related study using argon flowing into air was able to determine experimentally that $\mathrm{H}_{2} \mathrm{O}_{2}$ is produced via $\mathrm{OH}_{g}$ from the plasma, dissolved into the liquid as $\mathrm{OH}_{a q}$ (He et al. 2018):

$$
\begin{gathered}
\mathrm{OH}_{g} \rightarrow \mathrm{OH}_{a q} \\
\mathrm{OH}_{a q}+\mathrm{OH}_{a q} \rightarrow \mathrm{H}_{2} \mathrm{O}_{2 a q}
\end{gathered}
$$

(He et al. 2018) also concluded that the generation of $\mathrm{OH}_{a q}$ does not oecur by photolysis because $\mathrm{H}_{2} \mathrm{O}_{2}$ production is low when only plasma-produced UV photons are allowed to reach the liquid. They also deemed the transfer of gas-phase $\mathrm{H}_{2} \mathrm{O}_{2}$ into the liquid to be negligible.

Reactions R3-R4 are not the only the route to $\mathrm{H}_{2} \mathrm{O}_{2}$ that has been proposed. From a largely 0-D kinetic model of a DC glow discharge in ambient air with a water cathode, (Bobkova et al. 2014) concluded that even if the flux of gas-phase $\mathrm{OH}$ and $\mathrm{H}_{2} \mathrm{O}_{2}$ were completely dissolved into water, the growth rates of both species were too low to match experiment. With a separate but complementary model of the liquid chemistry, (Bobkova et al. 2012) succeeded in predicting the experimental values of $\mathrm{H}_{2} \mathrm{O}_{2}$ concentration, but reactions $\mathrm{R} 3-\mathrm{R} 4$ were not major contributors. Instead, ion bombardment emerged as the dominant route of $\mathrm{H}_{2} \mathrm{O}_{2}$ formation:

$$
\begin{gathered}
\mathrm{H}_{2} \mathrm{O}+\mathrm{ion} \rightarrow \mathrm{H}_{2} \mathrm{O}^{*} \\
\mathrm{H}_{2} \mathrm{O}^{*}+\mathrm{H}_{2} \mathrm{O} \rightarrow \mathrm{H}_{2}+\mathrm{H}_{2} \mathrm{O}_{2}
\end{gathered}
$$

Table 1 compiles the bulk production rates of aqueous PAW species, calculated towards the end of the plasma treatment time, for several studies of glow discharges generated in air with a water cathode. High current initially leads to high rates of $\mathrm{H}_{2} \mathrm{O}_{2}$ production at early times (Shutov et al. 2020), in accordance with reactions R5-R6. As mentioned above, reaction R1 implies that net $\mathrm{H}_{2} \mathrm{O}_{2}$ production diminishes at later times due to consumption to produce $\mathrm{NO}_{3}{ }^{-}$, as reflected by the production rates for these species reported by (He et al. 2017, Lu et al. 2017). The slowdown of $\mathrm{H}_{2} \mathrm{O}_{2}$ production is also apparent when comparing the rate reported by (Shutov et al. 2020) to that of (Bobkova et al. 2012), which is essentially the same experiment but at a later time.

The experimental conditions of the current study are close to those of (He et al. 2017) in terms of the discharge current and plasma treatment time, and the production rates of $\mathrm{H}_{2} \mathrm{O}_{2}$ and 
Revised manuscript to Journal of Physics D

$\mathrm{NO}_{3}{ }^{-}$are correspondingly similar. The conditions of (Bobkova et al. 2012) are even more similar, but $\mathrm{H}_{2} \mathrm{O}_{2}$ is produced at a noticeably higher rate. Figure 6(d) shows that the $\mathrm{H}_{2} \mathrm{O}_{2}$ concentration increases unsteadily, but by $120 \mathrm{~min}$ appears to have stagnated, and continues in this fashion until $428 \mathrm{~min}$ (not shown). Thus, even though the global growth rate is $11 \mu \mathrm{m} / \mathrm{min}$, the rate at the end of the plasma treatment time is reported as zero on Table 1.

Table 1: Summary of bulk production rates of aqueous PAW species from several experimental studies of glow discharges generated in atmospheric-pressure air with a water cathode. The rates represent the average value towards the end of the plasma treatment time. All the studies involve fixed volumes of liquid and acidic conditions ( $\mathrm{pH}=3-3.5$ ). The liquids are either deionized water (DIW) or aqueous solutions containing the listed solute.

\begin{tabular}{|c|c|c|c|c|c|c|c|c|}
\hline $\begin{array}{l}\text { Current } \\
(\mathrm{mA})\end{array}$ & Liquid & $\begin{array}{l}\text { Time } \\
\text { (min) }\end{array}$ & $\begin{array}{l}\text { Cell } \\
(\mathrm{mL})\end{array}$ & $\begin{array}{l}\mathrm{OH}_{a q} \\
(\mu \mathrm{M} / \mathrm{min})\end{array}$ & $\begin{array}{l}\mathrm{H}_{2} \mathrm{O}_{2} \\
(\mu \mathrm{M} / \mathrm{min})\end{array}$ & $\begin{array}{l}\mathrm{NO}_{2}^{-} \\
(\mu \mathrm{M} / \mathrm{min})\end{array}$ & $\begin{array}{l}\mathrm{NO}_{3}^{-} \\
(\mu \mathrm{M} / \mathrm{min})\end{array}$ & Reference \\
\hline 5 (DC) & $\begin{array}{l}\text { Ultrapure } \\
\mathrm{H}_{2} \mathrm{O}\end{array}$ & 428 & 24 & & & & 48 & This work \\
\hline $10(\mathrm{DC})$ & DIW & 30 & 80 & & 40 & & & $\begin{array}{l}\text { (Bobkova et al. } \\
2012 \text { ) }\end{array}$ \\
\hline $10(\mathrm{DC})$ & $\begin{array}{l}3800 \mu \mathrm{S} / \mathrm{cm} \\
\mathrm{NaCl}\end{array}$ & 30 & 100 & & $\sim 0$ & & 50 & (He et al. 2017) \\
\hline 15 (DC) & $\begin{array}{l}1 \mathrm{mM} \\
\mathrm{Fe}(\mathrm{CN})_{6}{ }^{4-}\end{array}$ & 5 & 0 & 10 & & & & $\begin{array}{l}\text { (Khlyustova et al. } \\
\text { 2016) }\end{array}$ \\
\hline $20(\mathrm{AC})$ & DIW & 15 & 10 & & $\sim 0$ & 137 & 98 & (Lu et al. 2017) \\
\hline 40 (DC) & DIW & & 80 & & 600 & $\begin{array}{l}\sim 0 \\
\end{array}$ & $\sim 0$ & $\begin{array}{l}\text { (Shutov et al. } \\
\text { 2020) }\end{array}$ \\
\hline
\end{tabular}

To provide a complete idea of the densities of the species involved in reaction $\mathrm{R} 3$, using laser-induced fluorescence (Nikiforov et al. 2011) measured the $\mathrm{OH}_{g}$ density to be $1.3 \times 10^{15} \mathrm{~cm}^{-3}$ in the positive column of a 10-mA DC glow discharge in air generated over a distilled water cathode. On the other hand, when a tap water cathode is used, a 13.4-mA DC glow discharge in air was measured by UV absorption to have an $\mathrm{OH}_{g}$ density of $1.7 \pm 0.33 \times 10^{17} \mathrm{~cm}^{-3}$, which extended out to a radius of $0.7 \pm 0.1 \mathrm{~mm}$ (Xiong et al. 2015). 
Revised manuscript to Journal of Physics D

\subsection{Interfacial region}

The most important result of the present work is the detection of a near-interface zone of enhanced liquid-phase chemistry that measures $28 \mu \mathrm{m}$ in depth. As discussed in section 3.2, this depth is subject to interpretation because of the shape of the meniscus created by the plasma. The existence of an interface layer with this approximate size is nonetheless clear. However, most recent numerical models of plasma-water interfaces do not reproduce such a layer for stable species such as $\mathrm{NO}_{3}{ }^{-}$.

First, consider studies with detailed modeling of the plasma and/or interface chemistry that employ drift/diffusion treatments of liquid transport. The only detailed model of the interface for a DC glow in contact with water, albeit for an aqueous $\mathrm{NaCl}$ solution in argon atmosphere (Gopalakrishnan et al. 2016), predicted a nm-scale surface layer with enhanced electron density, electric field, and densities of certain species $\left(\mathrm{OH}, \mathrm{OH}^{-}, \mathrm{H}^{+}\right)$as well as $\mathrm{pH}$. This model did not extend beyond $1 \mu \mathrm{m}$ in depth nor longer than the $\mu$ s timescale. Other models, though less similar to the present study in terms of the plasma, incorporated simulation domains sufficiently large for comparison. (Tian and Kushner 2014) showed that after three successive pulsed discharges and $1 \mathrm{~s}$ of afterglow, both the $\mathrm{H}_{2} \mathrm{O}_{2}$ and $\mathrm{NO}_{3}{ }^{-}$concentrations penetrated $100-200 \mu \mathrm{m}$ into the water. However, this model did not address how the gradients would evolve were the simulation extended to the timescales of the present study. (Liu et al. 2015$)^{3}$ considered a longer timescale, though for indirect plasma treatment. The penetration depths of both $\mathrm{H}_{2} \mathrm{O}_{2}$ and $\mathrm{NO}_{3}{ }^{-}$increased up to the mm scale by $100 \mathrm{~s}$, but the concentration profiles did not show any gradients within $100 \mu \mathrm{m}$ of the surface. However, both Tian et al. and Liu et al. reported penetration depths of $\sim 10 \mu \mathrm{m}$ for $\mathrm{OH}_{a q}$, despite different timescales of simulation.

The model of (Lindsay et al. 2015) imported plasma-generated species flux into the liquid from a separate model, but convection, heat transfer, and evaporation were considered in detail. This model predicted a gradient consistent with the present study after $1000 \mathrm{~s}$ for $\mathrm{ONOOH}$ and $\mathrm{OH}_{a q}$, whose interface depths were 30 and $50 \mu \mathrm{m}$, respectively. The gradients defining the edges of the layers for these species were also much steeper than reported by Liu et al. Furthermore, although reaction $\mathrm{R} 1$ is responsible for $\mathrm{ONOOH}$ production in the bulk liquid, a different reaction explained its increased density at the interface:

${ }^{3}$ In this section, this paper is referred to as Liu et al. 
Revised manuscript to Journal of Physics D

R7

$$
\mathrm{NO}_{2}+\mathrm{OH}_{a q} \rightarrow \mathrm{ONOOH}
$$

The reaction $\mathrm{R} 7$ is limited to the interface by the penetration depth of the short-lived $\mathrm{OH}_{a q}$, whereas reaction $\mathrm{R} 1$ can proceed in the bulk because $\mathrm{H}_{2} \mathrm{O}_{2}, \mathrm{NO}_{2}{ }^{-}$, and $\mathrm{H}^{+}$are long-lived. Tian et al. also remarked on the primacy of reaction $\mathrm{R} 7$ for generating $\mathrm{ONOOH}$ for a plasmain direct contact with water, such as is the case for Lindsay et al. and the present study.

Lindsay et al. did not include the deformation of the surface but argued that this did not have an appreciable impact on the results. Other models of a similar kind, namely a plasma jet in direct contact with water, assumed a deformation shape and modeled the fluid flow near the surface (Verlackt et al. 2018, Heirman et al. 2019). Near the interface, cross flows at the $100 \mu \mathrm{m}$ scale were clearly discerned. Again, the generation of ONOOH occurred mostly near the interface due to reaction $\mathrm{R} 7$, yet gradients of liquid species at the $\sim 10 \mu \mathrm{m}$ scale were not readily apparent.

Surface deformation was modeled explicitly by (Semenov et al. 2019), who focused on fluid mechanical effects resulting from the turbulence of the plasma jet and from swirling (azimuthal) flows. To account for the adsorption of gaseous species into the liquid by Henry's law (i.e. reaction $\mathrm{R} 3$ ), a diffusive boundary layer in the liquid with elevated species densities was estimated (not modeled) to be about $10 \mu \mathrm{m}$ deep and approximated as an infinitely thin boundary condition. As with other models, $\mathrm{H}_{2} \mathrm{O}_{2}$ achieved nearly uniform concentration in the liquid.

Thus, the appearance of interfacial layers $\sim 10 \mu \mathrm{m}$ has not been universal across models, even though there has been general agreement that reaction $\mathrm{R} 7$ biases ONOOH production towards the interface rather than the bulk liquid. Transport may play a role, and it is worthwhile to consider its impact more closely. A natural starting point is the transport of $\mathrm{OH}_{a q}$ due to its role in localizing reaction $\mathrm{R} 7$ to the interface. Let $L_{O H}$ be the penetration depth of $\mathrm{OH}_{a q}$. For a second-order reactiondiffusion problem (which would apply to reaction $\mathrm{R} 4$ ), $L_{\mathrm{OH}} \propto 1 / \sqrt{c_{\mathrm{OH}}}$ where $\mathrm{c}_{\mathrm{OH}}$ is the concentration of $\mathrm{OH}_{a q}$ (Lindsáy et al. 2015). Lindsay et al. used this scaling relation to argue that the depth of the interfacial region should always fall in the $\sim 1-100 \mu \mathrm{m}$ range. An inverse relationship of $\mathrm{L}_{\mathrm{OH}}$ with $\mathrm{COH}_{\mathrm{OH}}$ as well as with the flux of $\mathrm{OH}_{g}$ at the interface was also derived in the analytical model of (Rumbach et al. 2018) ${ }^{4}$ on the basis of reaction R4, but realistic values of $L_{O H}$ were found to be less than $1 \mu \mathrm{m}$, a result corroborated by (Gopalakrishnan et al. 2016).

\footnotetext{
${ }^{4}$ In this section, this paper is referred to as Rumbach et al.
} 
Revised manuscript to Journal of Physics D

Consider now the conditions of transport that would be necessary to produce the interfacial layer thickness reported in the present study. Taking the approach of Lindsay et al., the second Damkohler number for a second-order reaction-diffusion problem is $D a_{I I}=k c_{O H} L_{O H}^{2} / D_{O H}$. Following Rumbach et al., the diffusion coefficient of $\mathrm{OH}_{a q}$ at room temperature is $D_{O H}=2.3 \times 10^{-}$ ${ }^{9} \mathrm{~m}^{2} \mathrm{~s}^{-1}$, and the reaction coefficient for $\mathrm{H}_{2} \mathrm{O}_{2}$ formation (reaction $\mathrm{R} 4$ ) is $k=3.6 \times 10^{9} \mathrm{M}^{-1} \mathrm{~s}^{-1}$. The concentration of $\mathrm{OH}_{a q}$ at the interface is taken to be $4 \mu \mathrm{M}$ from the modeling study closest to the conditions of the present work (Gopalakrishnan et al. 2016). Assuming that the interfacial layers of $\mathrm{OH}_{a q}$ and $\mathrm{NO}_{3}{ }^{-}$have the same thickness, taking $L_{O H}=28 \mu \mathrm{m}$ from Figure 10 yields $D a_{\mathrm{II}}=4900$. For comparison, $D a_{I I}$ is $\sim 10^{4}$ and $\sim 10^{6}$ for the results of Lindsay et al. and Rumbach et al., respectively. The value for Rumbach et al. is the largest because the model is an ideal case involving only reaction $\mathrm{R} 4$. The smaller value of Lindsay et al. may reflect the influence of competing reactions and convection. The yet smaller estimate of $D a_{\mathrm{II}}$ for the present work also points in this direction.

To explore this possibility, consider the Péclet number for mass transfer: $P e=u L_{O H} / D$. The surface flow velocity may be estimated to be $u \sim 10 \mathrm{~cm} / \mathrm{s}$ based on modeling and experimental results (Shimizu et al. 2011, Lindsay et al. 2015, Thagard et al. 2018, Semenov et al. 2019), yielding $P e \sim 1200$. Thus, convective mass transport should bear some importance, making the first Damkohler number $D a=k c_{O H} \tau$ relevant to the analysis. The characteristic time of residence is estimated to be $\tau=L_{O H} / u=280 \mu \mathrm{s}$. This yields $D a=4$, which is neither large nor small. This implies that maintaining an $\mathrm{OH}_{a q}$ interfacial boundary layer with a depth of $L_{O H}=28 \mu \mathrm{m}$ under these conditions requires a balance between $\mathrm{H}_{2} \mathrm{O}_{2}$ production (reactions $\mathrm{R} 3-\mathrm{R} 4$ ) and convective losses. A similar length scale may be expected for the interfacial depth of ONOOH, given the findings of Lindsay et al.

The above estimates suggest that the physico-chemical environment of the interface predicted by several models allows for the existence of an interfacial layer of $\mathrm{OH}_{a q}$ that is $28 \mu \mathrm{m}$ deep if convection plays a role, but a number of caveats exist. The plasma-water reactors investigated by these models differ in important respects from the system of the present work and from each other. Also, reaction $\mathrm{R} 7$ serves as a sink for $\mathrm{OH}_{a q}$ and would tend to increase both Damkohler numbers. Most importantly, the underlying assumption has been that the interfacial layer of $\mathrm{OH}_{\mathrm{aq}}$ or $\mathrm{ONOOH}$ is representative of $\mathrm{NO}_{3}{ }^{-}$, but none of the above models has shown this to be true. 
Revised manuscript to Journal of Physics D

\section{Conclusion}

This study has reported the liquid-phase structure of the interfacial region of plasma-water interaction during PAW generation by a DC glow discharge in air generated over an ultrapure water cathode. The introduction of a light-sheet microscopy technique for performing Raman spectral imaging in one dimension enabled the in situ measurement of $\mathrm{NO}_{3}^{-}$and $\mathrm{H}_{2} \mathrm{O}_{2}$ concentrations with $\mu \mathrm{m}$-scale depth resolution. Tracking the concentrations in time confirmed that the bulk liquid concentration of $\mathrm{NO}_{3}{ }^{-}$grew linearly at $48 \mu \mathrm{M} / \mathrm{min}$. The bulk production of $\mathrm{H}_{2} \mathrm{O}_{2}$ was much slower and appeared to reach a plateau, attaining a final concentration of $5 \mathrm{mM}$ after $428 \mathrm{~min}$ of plasma treatment. These results were in line with the established mechanism linking $\mathrm{H}_{2} \mathrm{O}_{2}$ and $\mathrm{NO}_{3}{ }^{-}$in the bulk liquid (reactions R1-R2).

By modulating the water volume under detection near the interface, it was also possible to distinguish the chemistry of the interfacial region from that of the bulk liquid. The concentrations of $\mathrm{H}_{2} \mathrm{O}_{2}$ and $\mathrm{NO}_{3}{ }^{-}$both increased as the fractional water occupation of the detection volume $\left(f_{D V}\right)$ decreased below a critical value of 0.2 , corresponding to a depth of about $20 \mu \mathrm{m}$. The reconstruction of the depth profile of $\mathrm{NO}_{3}{ }^{-}$concentration showed the interfacial layer was $28 \mu \mathrm{m}$ deep, although this measurement remains approximate due to the complex shape of the meniscus created by the plasma. At the timescale of the present study, no existing model of the plasma-water interface has predicted such a localized region of excess $\mathrm{NO}_{3}{ }^{-}$concentration relative to the bulk liquid. An analysis of the interfacial layer of $\mathrm{OH}_{a q}$ showed that convection may play a role in defining its depth, if assumed to be $28 \mu \mathrm{m}$, along with diffusion and reactions forming $\mathrm{H}_{2} \mathrm{O}_{2}$ and $\mathrm{ONOOH}$ (R4 and R7, respectively).

The FWHM of $\mathrm{NO}_{3}{ }^{-}$was reported here to depend also on $f_{D V}$. There was clearly a difference between the bulk and interfacial regions. However, the quality of the experimental spectra of the present study was not yet sufficient for pursuing spectral lineshape analysis. Carrying out such an analysis and determining the physical or chemical cause of the narrowing/broadening of these bands will be the subject of future work.

\section{Acknowledgements}

Financial support is gratefully acknowledged from the Agence Nationale de la Recherche programs JCJC PLASMAFACE (ANR-15-CE06-0007-01) and "Investissements d'Avenir" LABEX INTERACTIFS (ANR-11-LABX-0017-01) of the French government, and the CPER- 
Revised manuscript to Journal of Physics D

FEDER program of the Région Nouvelle Aquitaine. The author also thanks Thomas Orrière of the Université de Poitiers for use of his current-sensing resistor circuit.

\section{7. $\quad$ References}

Batchelor, C. K. and G. Batchelor (2000). An introduction to fluid dynamics, Cambridge university press.

Bobkova, E., T. Shikova, V. Grinevich and V. Rybkin (2012). "Mechanism of hydrogen peroxide formation in electrolytic-cathode atmospheric-pressure direct-current discharge." High Energy Chemistry 46(1): 5659.

Bobkova, E. S., S. A. Smirnov, Y. V. Zalipaeva and V. V. Rybkin (2014). "Modeling chemical composition for an atmospheric pressure dc discharge in air with water cathode by 0-d model." Plasma chemistry and plasma processing 34(4): 721-743.

Bruggeman, P., L. Graham, J. Degroote, J. Vierendeels and C. Leys (2007). "Water surface deformation in strong electrical fields and its influence on electrical breakdown in a metal pin-water electrode system." Journal of Physics D-Applied Physics 40(16): 4779-4786.

Bruggeman, P., E. Ribežl, A. Maslani, J. Degroote, A. Malesevic, R. Rego, J. Vierendeels and C. Leys (2008). "Characteristics of atmospheric pressure air discharges with a liquid cathode and a metal anode." Plasma Sources Science and Technology 17(2): 025012.

Chen, Z., L. Lin, X. Cheng, E. Gjika and M. Keidar (2016). "Effects of cold atmospheric plasma generated in deionized water in cell cancer therapy." Plasma Processes and Polymers 13(12): 1151-1156.

Fanton, X., A. Cazabat and D. Quéré (1996). "Thickness and shape of films driven by a Marangoni flow." Langmuir 12(24): 5875-5880.

Girard, F., V. Badets, S. Blanc, K. Gazeli, L. Marlin, L. Authier, P. Svarnas, N. Sojic, F. Clément and S. Arbault (2016a). "Formation of reactive nitrogen species including peroxynitrite in physiological buffer exposed to cold atmospheric plasma." Rsc Advances 6(82): 78457-78467.

Girard, P.-M., A. Arbabian, M. Fleury, G. Bauville, V. Puech, M. Dutreix and J. S. Sousa (2016b). "Synergistic effect of $\mathrm{H} 2 \mathrm{O} 2$ and NO 2 in cell death induced by cold atmospheric He plasma." Scientific reports 6: 29098.

Gopalakrishnan, R., E. Kawamura, A. Lichtenberg, M. Lieberman and D. Graves (2016). "Solvated electrons at the atmospheric pressure plasma-water anodic interface." Journal of Physics D: Applied Physics 49(29): 295205.

Gorbanev, Y., A. Privat-Maldonado and A. Bogaerts (2018). Analysis of short-lived reactive species in plasma-air-water systems: the dos and the do nots, ACS Publications. 90: 13151-13158.

He, B., Y. Ma, X. Gong, Z. Long, J. Li, Q. Xiong, H. Liu, Q. Chen, X. Zhang and S. Yang (2017). "Simultaneous quantification of aqueous peroxide, nitrate, and nitrite during the plasma-liquid interactions by derivative absorption spectrophotometry." Journal of Physics D: Applied Physics 50(44): 445207. 


\section{Revised manuscript to Journal of Physics D}

He, X., J. Lin, B. He, L. Xu, J. Li, Q. Chen, G. Yue, Q. Xiong and Q. H. Liu (2018). "The formation pathways of aqueous hydrogen peroxide in a plasma-liquid system with liquid as the cathode." Plasma Sources Science and Technology 27(8): 085010.

Heirman, P., W. Van Boxem and A. Bogaerts (2019). "Reactivity and stability of plasma-generated oxygen and nitrogen species in buffered water solution: a computational study." Physical Chemistry Chemical Physics 21(24): 12881-12894.

Inagaki, Y. and K. Sasaki (2020). "Reactivity of solvated electrons in ionic liquid interacting with lowpressure plasmas." Japanese Journal of Applied Physics 59(6): 066001.

Jablonowski, H., J. S. Sousa, K.-D. Weltmann, K. Wende and S. Reuter (2018). "Quantification of the ozone and singlet delta oxygen produced in gas and liquid phases by a non-thermal atmospheric plasma with relevance for medical treatment." Scientific reports 8(1): 1-12.

Kamgang-Youbi, G., J.-M. Herry, J.-L. Brisset, M.-N. Bellon-Fontaine, A. Doubla and M. Naïtali (2008). "Impact on disinfection efficiency of cell load and of planktonic/adherent/detached state: case of Hafnia alvei inactivation by plasma activated water." Applied microbiology and biotechnology 81(3): 449-457.

Khlyustova, A., N. Khomyakova, N. Sirotkin and Y. Marfin (2016). "The effect of pH on OH radical generation in aqueous solutions by atmospheric pressure glow discharge." Plasma Chemistry and Plasma Processing 36(5): 1229-1238.

Labbaye, T., A. Canizares, M. Gaillard, T. Lecas, E. Kovacevic, C. Boulmer-Leborgne, T. Strunskus, N. Raimboux, P. Simon and G. Guimbretière (2014). "In situ Raman spectroscopy for growth monitoring of vertically aligned multiwall carbon nanotubes in plasma reactor." Applied Physics Letters 105(21): 213109.

Li, Z., H. Li, W. Fang, S. Wang, C. Sun, Z. Li and Z. Men (2015). "Pre-resonance-stimulated Raman scattering for water bilayer structure on laser-induced plasma bubble surface." Optics Letters 40(14): 32533255 .

Lide, D. R. (1995). CRC handbook of chemistry and physics: a ready-reference book of chemical and physical data, CRC press.

Lieber, C. A. and A. Mahadevan-Jansen (2003). "Automated method for subtraction of fluorescence from biological Raman spectra." Applied spectroscopy 57(11): 1363-1367.

Lindsay, A., C. Anderson, E. Slikboer, S. Shannon and D. Graves (2015). "Momentum, heat, and neutral mass transport in convective atmospheric pressure plasma-liquid systems and implications for aqueous targets." Journal of Physics D: Applied Physics 48(42): 424007.

Liu, Y., H. Zhang, J. Sun, J. Liu, X. Shen, J. Zhan, A. Zhang, S. Ognier, S. Cavadias and P. Li (2018). "Degradation of aniline in aqueous solution using non-thermal plasma generated in microbubbles." Chemical Engineering Journal 345: 679-687.

Liu, Z., D. Liu, C. Chen, D. Li, A. Yang, M. Rong, H. Chen and M. Kong (2015). "Physicochemical processes in the indirect interaction between surface air plasma and deionized water." Journal of Physics D: Applied Physics 48(49): 495201. 
Revised manuscript to Journal of Physics D

Lo, A., A. Cessou, P. Boubert and P. Vervisch (2014). "Space and time analysis of the nanosecond scale discharges in atmospheric pressure air: I. Gas temperature and vibrational distribution function of N2 and O2." Journal of Physics D: Applied Physics 47(11): 115201.

Lu, P., D. Boehm, P. Bourke and P. J. Cullen (2017). "Achieving reactive species specificity within plasmaactivated water through selective generation using air spark and glow discharges." Plasma Processes and Polymers 14(8): 1600207.

Lukes, P., E. Dolezalova, I. Sisrova and M. Clupek (2014). "Aqueous-phase chemistry and bactericidal effects from an air discharge plasma in contact with water: evidence for the formation of peroxynitrite through a pseudo-second-order post-discharge reaction of $\mathrm{H} 2 \mathrm{O} 2$ and HNO2." Plasma Sources Science and Technology 23(1): 015019.

Machala, Z., B. Tarabova, K. Hensel, E. Spetlikova, L. Sikurova and P. Lukes (2013). "Formation of ROS and RNS in Water Electro-S prayed through Transient Spark Discharge in Air and their Bactericidal Effects." Plasma Processes and Polymers 10(7): 649-659.

Machala, Z., B. Tarabová, D. Sersenová, M. Janda and K. Hensel (2018). "Chemical and antibacterial effects of plasma activated water: correlation with gaseous and aqueous reactive oxygen and nitrogen species, plasma sources and air flow conditions." Journal of Physics D: Applied Physics 52(3): 034002.

Nayak, G., A. J. Andrews, I. Marabella, H. A. Aboubakr, S. M. Goyal, B. A. Olson, M. Torremorell and P. J. Bruggeman (2020). "Rapid inactivation of airborne porcine reproductive and respiratory syndrome virus using an atmospheric pressure air plasma." Plasma Processes and Polymers: e1900269.

Nikiforov, A., Q. Xiong, N. Britun, R. Snyders, X. P. Lu and C. Leys (2011). "Absolute concentration of $\mathrm{OH}$ radicals in atmospheric pressure glow discharges with a liquid electrode measured by laser-induced fluorescence spectroscopy." Applied physics express 4(2): 026102.

Orriere, T., D. Kurniawan, Y.-C. Chang, D. Z. Pai and W.-H. Chiang (2020). "Effect of plasma polarity on the synthesis of graphene quantum dots by atmospheric-pressure microplasmas." Nanotechnology 31(48): 485001 .

Pai, D. Z., F. Pailloux and D. Babonneau (2019). "In situ Raman spectroscopy of nanostructuration by surface plasmas generated on alumina thin film-silicon bilayers." Plasma Sources Science and Technology 28(8): 085007.

Pai, D. Z., S. Stauss and K. Terashima (2015). "Field-emitting Townsend regime of surface dielectric barrier discharges emerging at high pressure up to supercritical conditions." Plasma Sources Science and Technology 24(2): 025021.

Ritter, J. G., J.-H. Spille, T. Kaminski and U. Kubitscheck (2011). "A cylindrical zoom lens unit for adjustable optical sectioning in light sheet microscopy." Biomedical optics express 2(1): 185-193.

Rumbach, P., D. M. Bartels and D. B. Go (2018). "The penetration and concentration of solvated electrons and hydroxyl radicals at a plasma-liquid interface." Plasma Sources Science and Technology 27(11): 115013.

Rumbach, P., D. M. Bartels, R. M. Sankaran and D. B. Go (2015a). "The effect of air on solvated electron chemistry at a plasma/liquid interface." Journal of Physics D: Applied Physics 48(42): 424001. 


\section{Revised manuscript to Journal of Physics D}

Rumbach, P., D. M. Bartels, R. M. Sankaran and D. B. Go (2015b). "The solvation of electrons by an atmospheric-pressure plasma." Nature communications 6.

Semenov, I., K. Weltmann and D. Loffhagen (2019). "Modelling of the transport phenomena for an atmospheric-pressure plasma jet in contact with liquid." Journal of Physics D: Applied Physics 52(31): 315203.

Shimizu, T., Y. Iwafuchi, G. E. Morfill and T. Sato (2011). "Formation of thermal flow fields and chemical transport in air and water by atmospheric plasma." New Journal of Physics 13(5): 053025.

Shutov, D., N. Batova and V. Rybkin (2020). "Comparative Kinetics of Changing Chemical Composition of Liquid Water Anode and Cathode of DC Glow Discharge in Air." High Energy Chemistry 54(1): 59-63.

Sirotkin, N. and V. Titov (2017). "Transfer of liquid cathode components to the gas phase and their effect on the parameters of the atmospheric pressure dc discharge." Plasma Chemistry and Plasma Processing 37(6): 1475-1490.

Tachibana, K. and K. Yasuoka (2020). "Understanding of chemical reactions induced by argon plasma in contact with sodium halide solutions: importance of surface properties for plasma-liquid interactions." Journal of Physics D: Applied Physics 53(12): 125203.

Thagard, S. M., G. R. Stratton, M. Vasilev, P. Conlon and D. Bohl (2018). "An Experimental Investigation of the Liquid Flow Induced by a Pulsed Electrical Discharge Plasma." Plasma Chemistry and Plasma Processing 38(4): 719-741.

Tian, W. and M. J. Kushner (2014). "Atmospheric pressure dielectric barrier discharges interacting with liquid covered tissue." Journal of Physies D: Applied Physics 47(16): 165201.

Tomai, T., H. Yui and K. Terashima (2009). "Raman'spectroscopy of reaction fields induced by plasma in supercritical CO $2 . "$ Applied Physics Letters 94(15)! 151501-151501-151503.

Tresp, H., M. U. Hammer, J. Winter, K. Weltmann and S. Reuter (2013). "Quantitative detection of plasmagenerated radicals in liquids by electron paramagnetic resonance spectroscopy." Journal of Physics D: Applied Physics 46(43): 435401.

Verlackt, C., W. Van Boxem and A. Bogaerts (2018). "Transport and accumulation of plasma generated species in aqueous solution." Physical Chemistry Chemical Physics 20(10): 6845-6859.

Verreycken, T., A. Van Gessel, A. Pageau and P. Bruggeman (2011). "Validation of gas temperature measurements by OES in an atmospheric air glow discharge with water electrode using Rayleigh scattering." Plasma Sources Science and Technology 20(2): 024002.

Xiong, Q., Z. Yang and P. J. Bruggeman (2015). "Absolute OH density measurements in an atmospheric pressure de glow discharge in air with water electrode by broadband UV absorption spectroscopy." Journal of Physics D: Applied Physics 48(42): 424008.

Yamamoto, T., M. Okubo, N. Imai and Y. Mori (2004). "Improvement on hydrophilic and hydrophobic properties of glass surface treated by nonthermal plasma induced by silent corona discharge." Plasma Chemistry and Plasma Processing 24(1): 1-12. 
Revised manuscript to Journal of Physics D

Yang, J.-S., D. Z. Pai and W.-H. Chiang (2019). "Microplasma-enhanced synthesis of colloidal graphene quantum dots at ambient conditions." Carbon 153: 315-319.

Yui, H., H. Fujiwara and T. Sawada (2002). "Spectroscopic analysis of total-internal-reflection stimulated Raman scattering from the air/water interface under the strong focusing condition." Chemical physics letters 360(1-2): 53-58.

Yui, H., H. Kato and Y. Someya (2008). "Characteristic wavenumber shifts of the stimulated Raman scattering from interfacial water molecules induced by laser-induced plasma generation at air-water and water-silver interfaces." Journal of Raman Spectroscopy 39(11): 1688-1693.

Yui, H., Y. Yoneda, T. Kitamori and T. Sawada (1999). "Spectroscopic analysis of stimulated Raman scattering in the early stage of laser-induced breakdown in water." Physical review letters 82(20): 4110.

Zhang, S., A. Rousseau and T. Dufour (2017). "Promoting lentil germination and stem growth by plasma activated tap water, demineralized water and liquid fertilizer." RSC advances 7(50): 31244-31251.

Zhang, Z.-M., S. Chen and Y.-Z. Liang (2010). "Baseline correction using adaptive iteratively reweighted penalized least squares." Analyst 135(5): 1138-1146.

Zhou, R., R. Zhou, P. Wang, Y. Xian, A. Mai-Prochnow, X. P. Lu, P. Cullen, K. K. Ostrikov and K. Bazaka (2020). "Plasma activated water (PAW): generation, origin of reactive species and biological applications." Journal of Physics D: Applied Physics.

Zhou, R., R. Zhou, X. Zhang, J. Zhuang, S. Yang, K. Bazaka and K. K. Ostrikov (2016). "Effects of atmospheric-pressure N 2, He, air, and O 2 microplasmas on mung bean seed germination and seedling growth." Scientific reports 6: 32603. 